\title{
Sodium New Houttuyfonate Inhibits Candida albicans Biofilm Formation by Inhibiting the Ras1-cAMP-Efg1 Pathway Revealed by RNA-seq
}

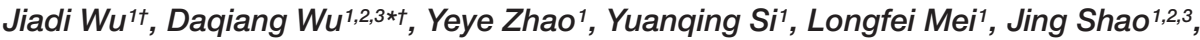 \\ Tianming Wang ${ }^{3}$, Guiming Yan ${ }^{3 *}$ and Changzhong Wang ${ }^{1,2,3 *}$
}

'Department of Pathogenic Biology and Immunology, College of Integrated Chinese and Western Medicine, Anhui University of Chinese Medicine, Hefei, China, ${ }^{2}$ Research Institute of Integrated Traditional Chinese and Western Medicine, Anhui

OPEN ACCESS

Edited by:

Sujogya Kumar Panda,

KU Leuven, Belgium

Reviewed by:

Shunmugiah Karutha Pandian,

Alagappa University, India

Sudhanshu Shukla,

Amity University, India

Rodnei Dennis Rossoni.

São Paulo State University, Brazil

*Correspondence:

Daqiang Wu

daqwu@126.com

Guiming Yan

922-119@163.com

Changzhong Wang

ahwcz63@sina.com

${ }^{\dagger}$ These authors have contributed equally to this work

Specialty section: This article was submitted to Antimicrobials, Resistance and Chemotherapy,

a section of the journal Frontiers in Microbiology

Received: 24 April 2020 Accepted: 06 August 2020

Published: 25 August 2020

Citation:

Wu J, Wu D, Zhao Y, Si Y, Mei L, Shao J, Wang $T$, Yan $G$ and Wang $C$ (2020) Sodium New Houttuyfonate

Inhibits Candida albicans Biofilm Formation by Inhibiting the Ras1-CAMP-Efg1 Pathway

Revealed by RNA-seq

Front. Microbiol. 11:2075

doi: 10.3389/fmicb.2020.02075
University of Chinese Medicine, Hefei, China, ${ }^{3}$ Key Laboratory of Chinese Herbal Compound Formula in Anhui Province, Hefei, China

Here, we aim to investigate the antifungal effect and mechanism of action of sodium new houttuyfonate $(\mathrm{SNH})$ against Candida albicans. Microdilution analysis results showed that SNH possesses potent inhibitory activity against C. albicans SC5314, with a $\mathrm{MIC}_{80}$ of $256 \mu \mathrm{g} / \mathrm{mL}$. Furthermore, we found that $\mathrm{SNH}$ can effectively inhibit the initial adhesion of C. albicans. Inverted microscopy, crystal violet staining, scanning electron microscopy and confocal laser scanning microscopy results showed that morphological changes during the transition from yeast to hypha and the biofilm formation of $\mathrm{C}$. albicans are repressed by $\mathrm{SNH}$ treatment. We also found that $\mathrm{SNH}$ can effectively inhibit the biofilm formation of clinical C. albicans strains (Z103, Z3044, Z1402, and Z1407) and SNH in combination with fluconazole, berberine chloride, caspofungin and itraconazole antifungal agents can synergistically inhibit the biofilm formation of C. albicans. Eukaryotic transcriptome sequencing and qRT-PCR results showed that $\mathrm{SNH}$ treatment resulted in significantly down-regulated expression in several biofilm formation related genes in the Ras1-cAMP-Efg1 pathway (ALS1, ALA1, ALS3, EAP1, RAS1, EFG1, HWP1, and TEC1) and significantly up-regulated expression in yeast formassociated genes (YWP1 and RHD1). We also found that SNH can effectively reduce the production of key messenger CAMP in the Ras1-cAMP-Efg1 pathway. Furthermore, using Galleria mellonella as an in vivo model we found that $\mathrm{SNH}$ can effectively treat C. albicans infection in vivo. Our presented results suggest that $\mathrm{SNH}$ exhibits potential antibiofilm effects related to inhibiting the Ras1-CAMP-Efg1 pathway in the biofilm formation of $C$. albicans.

Keywords: Candida albicans, sodium new houttuyfonate, anti-adhesive, anti-biofilm, Ras1-cAMP-Efg1 pathway

\footnotetext{
Abbreviations: AOD, average optical density; BBR, berberine chloride; cAMP, cyclic adenosine monophosphate; CAS, caspofungin; cDNA, complementary deoxyribonucleic acid; CFU, colony-forming unit; CLSM, confocal laser scanning microscopy; DEPC, diethypyrocarbonate; FIC, fractional inhibitory concentration; FICI, fractional inhibitory concentration index; FLZ, fluconazole; GO, gene ontology; ITZ, itraconazole; $\mathrm{LD}_{50}$, lethal dose 50\%; MFC, minimum fungicidal concentrations; $\mathrm{MIC}_{80}$, minimum inhibitory concentrations of $80 \%$; PBS, phosphate-buffered saline; PC, principal component; PCA, principle component analysis; PCR, polymerase chain reaction; qRT-PCR, quantitative reverse transcription polymerase chain reaction; RNA, ribonucleic acid; SEM, scanning electron microscopy; SNH, sodium new houttuyfonate; XTT, 2,3-Bis-(2-methoxy-4-nitro-5-sulfophenyl)-2H-tetrazolium-5-carboxanilide.
} 


\section{INTRODUCTION}

Fungal infections caused by Candida albicans, an opportunistic fungal pathogen (Naglik et al., 2006), are a growing threat in the immune deficient population (Wang et al., 2018), and C. albicans is the species most frequently implicated in different forms of invasive candidiasis (Rodriguezcerdeira et al., 2019). C. albicans is a dimorphic yeast that can interconvert from a yeast state to a hyphal state, commonly existing in mucosae and the digestive tract (Pizarrocerda and Cossart, 2006; Martin et al., 2018). Adherence of $C$. albicans to host cells, a prerequisite for infection, plays a significant role in pathogenesis, as it allows the establishment of a strong link to host cell surfaces and provides a focal point for infection by enabling persistence in harsh conditions (Pizarrocerda and Cossart, 2006; Martin et al., 2018). This high adherence is the main cause of fungal infection in human hosts, indicating that the highly infectious nature of this fungus may be related to its strong adherence capacity (Albrecht et al., 2006).

Numerous human infections are caused by biofilms of pathogenic microorganisms, especially fungi (Oshiro et al., 2019). Biofilm formation is initiated through adherence (Simon et al., 2018). Biofilms are complex microbial communities organized in an extracellular polymeric matrix comprising proteins, polysaccharides and DNA (Simon et al., 2018). Biofilm formation is a major concern in the clinic, as biofilms allow microorganisms to become significantly more resistant to antifungal agents and host immune clearance (Holm et al., 2015). The adhesion and biofilm formation of $C$. albicans significantly increases the risk of fungal infections with possible lethal complications (Tan et al., 2019). Therefore, new anti-adherence and anti-biofilm agents and strategies for C. albicans are urgently needed.

Natural products have been used as traditional medicines since ancient times (Boufridi and Quinn, 2018). Houttuynia cordata is an edible vegetable with a fishy taste which is widely consumed in southwest China, and also a traditional Chinese herb for treating lung and skin infections caused by pathogenic bacteria and fungi (Lu et al., 2013). Recent studies have indicated that Houttuynia cordata and its active ingredients demonstrate cogent antibacterial, anti-inflammatory, antiviral and anti-lung cancer activities (Jiang et al., 2019). The main effective component of Houttuynia cordata is sodium houttuyfonate ( $\mathrm{SH}$ ) which has a fishy odor, and has been widely used for the treatment of purulent skin infections and respiratory tract infections in China (Jiang et al., 2019). SH is not only effective against gram positive bacteria (Ye et al., 2007), but is also effective against fungi, and can be used as a synergistic companion with FLZ against C. albicans (Huang et al., 2015; Shao et al., 2017). Because of the instability of the chemical structure of $\mathrm{SH}$, its derivative, $\mathrm{SNH}$, has been synthesized with improved stability, and it also has a fishy odor ( $\mathrm{Lu}$ et al., 2013). SNH has been widely used in pharmaceutical and medical applications in China and demonstrates extensive biological and antimicrobial properties (Yang et al., 2016). Previous studies have shown that SNH can significantly inhibit a variety of bacteria through $\mathrm{H}_{2} \mathrm{O}_{2}$ stress ( $\mathrm{Wu}$ et al., 2015; Yang et al., 2016). However, the antifungal mechanism of SNH remains unclear. Therefore, we performed an RNA-seq assay to investigate the transcriptome changes in C. albicans treated using SNH. The transcription of genes involved in $\mathrm{H}_{2} \mathrm{O}_{2}$ stress was not significantly changed by $\mathrm{SNH}$ in C. albicans, implying that the antifungal mechanism of $\mathrm{SNH}$ may not be similar to its antibacterial mechanisms.

Therefore, in the current study, we aim to investigate the effects of $\mathrm{SNH}$ on the adherence and biofilm formation of C. albicans both in vitro and in vivo, and the possible antifungal mechanisms of SNH.

\section{MATERIALS AND METHODS}

\section{Strain and Cultivation}

Candida albicans SC5314 was a gift from Prof. Yuanying Jiang, School of Pharmacy, Second Military Medical University (Shanghai, China). C. albicans Z103, Z3044, Z1402, and Z1407 were purchased from the Clinical Laboratory of Anhui Provincial Hospital (Hefei, China). C. albicans was streaked from $-80^{\circ} \mathrm{C}$ glycerol stocks onto Sabouraud's agar (Hope Biotech Co., Qingdao, China) plates. The strain was routinely inoculated for three generations in Sabouraud's agar plates, a single colony was chosen for each inoculation, and then this was activated and propagated in liquid Sabouraud medium (Hope Biotech Co., Qingdao, China) at $37^{\circ} \mathrm{C}$ for $12-16 \mathrm{~h}$ until the strain reached the exponential growth phase. The revived Candida cells were pooled through centrifugation at 3000 g. After washing twice using sterile PBS (Leagene, Beijing, China), the Candida cells were resuspended in RPMI-1640 medium (Invitrogen, Carlsbad, CA, United States) and adjusted to a defined cell density using a hemocytometer prior to subsequent tests.

\section{Determination of Minimum Inhibitory Concentrations of $\mathbf{8 0} \%\left(\mathrm{MIC}_{\mathbf{8 0}}\right)$}

Sodium new houttuyfonate, (HPLC $\geq 98 \%$ ) was purchased from Shanghai Yuanye Bio-Technology Co., Ltd., and the production batch number was A23A9E59436. The C. albicans was diluted to $2 \times 10^{3} \mathrm{CFU} / \mathrm{mL}$. The minimum inhibitory concentration of $80 \%\left(\mathrm{MIC}_{80}\right)$ of $\mathrm{SNH}$ was determined in a 96-well flat-bottomed microplate (Corning, NA, United States) using the microdilution method. The SNH was serially two-fold diluted in a range of 1024-32 $\mu \mathrm{g} / \mathrm{mL}$. The fungal cells were incubated with the drugs used at $37^{\circ} \mathrm{C}$ for $24 \mathrm{~h}$, and the OD value of each well was measured at $620 \mathrm{~nm}$ using a microplate reader. The value of the control well was controlled at approximately 0.2 , and compared with the control well, the drug concentration in the lowest concentration well where the OD value decreased by more than $80 \%$ represented the $\mathrm{MIC}_{80}$ (the drug concentration when fungal growth was inhibited by $80 \%)$. The above experiment was repeated three times in parallel. It is accepted that when the $\mathrm{MIC}_{80}$ value can be accurately repeated or with only one concentration difference, then the higher concentration is used as the $\mathrm{MIC}_{80}$ value; when the $\mathrm{MIC}_{80}$ value differs by more than two concentrations, a re-test is needed until the requirements are met (Barchiesi et al., 1994; Pfaller and Barry, 1994). 


\section{Determination of Minimum Fungicidal Concentrations (MFC)}

To determine the minimum fungicidal concentration (MFC), $20 \mu \mathrm{L}$ of medium was removed from the 96-well plate for MIC detection and diluted 100-fold in PBS, and added to a solid sand agar plate, spread evenly, and then placed in a $37^{\circ} \mathrm{C}$ incubator for $24 \mathrm{~h}$, before counting the number of colonies (Silva et al., 2019). The MFC was determined as the lowest drug concentration such that fewer than three fungal colonies were observed after a $24 \mathrm{~h}$ incubation at $35^{\circ} \mathrm{C}$. The MFC determinations were repeated three times.

\section{Initial Adhesive Growth Curve}

The C. albicans solution was diluted to $2 \times 10^{6} \mathrm{CFU} / \mathrm{mL}$. After 0,2 and $4 \mathrm{~h}$ of incubation, the fungal solution for each group in each time period was placed on a mixing shaker to fully shake it, until the cells adhering to the bottom of the tube were completely resuspended in the culture medium. Immediately, $100 \mu \mathrm{L}$ of the suspension containing Candida for each group was serially diluted 1000-fold in PBS. The diluted suspension containing Candida was placed on the mixing shaker again, and fully shaken and mixed at the same time and frequency. A total of $100 \mu \mathrm{L}$ of the 1000-fold diluted suspension was then evenly plated on Sabouraud's agar in triplicate for a $24 \mathrm{~h}$ incubation at $37^{\circ} \mathrm{C}$ for yeast cell counting.

\section{XTT Reduction Assays}

Candida albicans cell culture medium $\left(100 \mu \mathrm{L} ; 2 \times 10^{6}\right.$ $\mathrm{CFU} / \mathrm{mL}$ ) was co-incubated with the same volumes of $\mathrm{SNH}$ or FLZ in a 96-well flat-bottomed microplate at $37^{\circ} \mathrm{C}$ for $2 \mathrm{~h}$ and $4 \mathrm{~h}$ (for adherence) or $24 \mathrm{~h}$ (for biofilms). The XTT salt [2,3-bis(2-methoxy-4-nitro-5-sulfophenyl)2Htetrazolium-5-carboxanilide sodium salt] (Shanghai Yuanye Bio-Technology Co., Ltd., Shanghai, China) was dissolved in Ringer's solution at a final concentration of $0.5 \mathrm{mg} / \mathrm{mL}$. Immediately before each assay, a menadione (Shanghai Dibai Biotechnology Co., Ltd., Shanghai, China) solution was prepared at a final concentration of $0.4 \mathrm{mM}$ and filter-sterilized. The XTT solution was mixed with the menadione solution at a ratio of 20:1 (v/v). Each well was washed twice with $200 \mu \mathrm{L}$ of sterile PBS to remove planktonic cells, and finally $50 \mu \mathrm{L}$ of newly prepared XTT solution was added to each well (Manoharan et al., 2017a; Rossoni et al., 2019). All well plates were incubated for $30 \mathrm{~min}$ in the dark, and colorimetric changes in the solutions were measured using a microplate reader (Thermo Labserv K3, Beijing, China) at $492 \mathrm{~nm}$.

\section{Inverted Microscope}

Candida albicans cell culture medium $\left(1 \mathrm{~mL} ; 2 \times 10^{6} \mathrm{CFU} / \mathrm{mL}\right)$ was co-incubated with the same volumes of SNH or FLZ in a 6-well flat-bottomed microplate at $37^{\circ} \mathrm{C}$ for $4 \mathrm{~h}$ (for yeast) and $6 \mathrm{~h}$ (for hyphae). After that, all plates were observed using a high-power lens $(\times 400)$ and photographed using the OLYMPUS IX51 (Tokyo, Japan).

\section{Quantitative Determination of Biofilms Using Crystal Violet}

As previously reported (Manoharan et al., 2017b), C. albicans was inoculated into 96-well plates for a static biofilm formation assay. Overnight cultures of $C$. albicans strains were inoculated into Potato Dextrose Broth (PDB, Hangwei, Hangzhou, China) at a $600 \mathrm{~nm}$ initial turbidity of 0.05 (total volume of $200 \mu \mathrm{L}$ ), with or without essential oils or different concentrations of its main components $(0.0005$ to $0.05 \%$, incubate under $\mathrm{v} / \mathrm{v}$ or w $/ \mathrm{v})$ for $24 \mathrm{~h}$, without shaking, at $37^{\circ} \mathrm{C}$. The samples were washed twice using sterile PBS to remove all non-adherent planktonic cells, and then stained with crystal violet (Macklin, Shanghai, China) for 20 min, washed gently with sterile PBS twice and stained with crystal violet with $95 \%$ ethanol to quantify biofilm formation. The absorbance of each well was measured at a wavelength of $570 \mathrm{~nm}$, and the results were calculated by averaging the data.

\section{Crystal Violet Staining}

As previously reported (Manoharan et al., 2017c), slides with an area of $1 \mathrm{~cm}^{2}$ were soaked in a $75 \%$ ethanol solution for $24 \mathrm{~h}$, washed with sterile PBS, and placed in a 6-well plate. C. albicans cell culture medium $\left(1 \mathrm{~mL} ; 2 \times 10^{6} \mathrm{CFU} / \mathrm{mL}\right)$ was co-incubated with the same volumes of SNH or FLZ in a 6well flat-bottomed microplate at $37^{\circ} \mathrm{C}$ for $24 \mathrm{~h}$ (for biofilms). After that, the upper layer medium was discarded and rinsed with sterile PBS three times, stained with crystal violet solution, observed using a high-power lens $(\times 400)$ and photographed using an OLYMPUS BX51 (Tokyo, Japan).

\section{Confocal Laser Scanning Microscopy (CLSM)}

Candida albicans cell culture medium $\left(500 \mu \mathrm{L} ; 2 \times 10^{6} \mathrm{CFU} / \mathrm{mL}\right)$ was co-incubated with the same volumes of SNH or FLZ in a $15 \mathrm{~mm}$ glass-bottom confocal dish (Biosharp, Hefei, China) at $37^{\circ} \mathrm{C}$ for $24 \mathrm{~h}$. After that, the upper layer medium was discarded and the dish was rinsed gently with PBS twice to remove planktonic fungi. Acridine orange dye solution $(1 \mathrm{mg} / \mathrm{mL}$, Yanye, Shanghai, China) was diluted to a final concentration of $0.01 \%$ in PBS, and then $200 \mu \mathrm{L}$ of $0.01 \%$ acridine orange dye solution was added into the confocal dish and incubated for $30 \mathrm{~min}$ in the dark. Finally, a photograph was obtained using a camera mounted on a laser scanning confocal microscope at an excitation wavelength of $488 \mathrm{~nm}$, and the AOD of the fluorescence in the photo was analyzed using Image $\mathrm{J}$.

\section{Scanning Electron Microscopy (SEM)}

Slides with an area of $1 \mathrm{~cm}^{2}$ were soaked in a 75\% ethanol solution for $24 \mathrm{~h}$, washed with sterile PBS, and placed in a 6-well plate. C. albicans cell culture medium $\left(1 \mathrm{~mL} ; 2 \times 10^{6}\right.$ $\mathrm{CFU} / \mathrm{mL}$ ) was co-incubated with the same volumes of $\mathrm{SNH}$ or FLZ in a 6-well flat-bottomed microplate at $37^{\circ} \mathrm{C}$ for $24 \mathrm{~h}$ (for biofilm). The slides were rinsed gently with PBS twice to remove planktonic fungi, and then placed in pre-chilled $2.5 \%$ glutaraldehyde solution and fixed for $2 \mathrm{~h}$ in the dark. The slides were then placed in an ethanol solution for gradient dehydration (30\%, $10 \mathrm{~min} ; 70 \%, 10 \mathrm{~min} ; 90 \%, 10 \mathrm{~min} ; 100 \%$, 
$10 \mathrm{~min}$ ), taken out and place in a ventilated and dry place to dry overnight. The glass slides were stuck in a metal plate using carbon tape and placed in a vacuum gold-plating machine for vacuum and gold plating. After the sample was prepared, it was placed into a Schottky Field Emission Scanning Electron Microscope (GeminiSEM 500, Germany) for observation $(\times 500)$ and to acquire images.

\section{An Assessment of Synergy Between SNH and Several Antifungal Agents}

Four antifungal agents were investigated: FLZ (HPLC $\geq 98 \%$ ), BBR (HPLC $\geq 98 \%$ ), CAS (HPLC $\geq 98 \%$ ), and ITZ (HPLC $\geq 98 \%$ ), which were purchased from Shanghai Yuanye Bio-Technology Co., Ltd. First, we tested the $\mathrm{MIC}_{80}$ concentration of these four antifungal agents alone against Candida albicans SC5314 through 96 well microplate experiments. After that, we combined these four antifungal agents with $\mathrm{SNH}$ separately, and conducted synergistic $\mathrm{MIC}_{80}$ experiments through a checkerboard microdilution method; that is, the two drugs were used in combination on a 96-well plate in a two-dimensional checkerboard longitudinal (A to $\mathrm{H}$ ) and horizontal (2 to 11) two-fold dilution in two directions, respectively. For example, for the combined use of $\mathrm{SNH}$ and FLZ, the final concentration of $\mathrm{SNH}$ was controlled at 2$256 \mu \mathrm{g} / \mathrm{mL}$, and the final concentration of FLZ was controlled at $0.005-4 \mu \mathrm{g} / \mathrm{mL}$. The final concentration ranges of the other antifungal agents used in combination with $\mathrm{SNH}$ were as follows: the final concentration of BBR was controlled at $0.125-64 \mu \mathrm{g} / \mathrm{mL}$, the final concentration of CAS was controlled at $0.005-4 \mu \mathrm{g} / \mathrm{mL}$, and the final concentration of ITZ was controlled at $0.01-8 \mu \mathrm{g} / \mathrm{mL}$.

Evaluation of the effect of combination medicine: The FICI is the main parameter for evaluating the interaction mode of two drugs. The FIC is the ratio of the MIC required for each drug when combined for antimicrobial activity and the MIC when used alone. FICI is equal to the sum of the FIC of the two drugs. This experiment used the latest standards of international journals: the interaction between the two drugs is determined to be synergistic when FICI $\leq 0.5$, it is an irrelevant effect when $0.5<$ FICI $\leq 4$, and when FICI $>4$, the two drugs produce an antagonistic effect.

We also used CLSM to observe the effect of SNH combined with several antifungal agents on a Candida albicans SC5314 biofilm, and set up a Control group, a MIC FLZ group, a MIC BBR group, a MIC CAS group, a MIC ITZ group and the above four drugs combined with MIC SNH group. The analysis method is consistent with the CLSM method described previously, and the AOD of the fluorescence in the photo was analyzed using Image $\mathrm{J}$.

\section{Eukaryotic Transcriptome Sequencing}

Candida albicans cells were harvested by centrifugation and the pellet was flash-frozen in liquid nitrogen. (1) Total RNA was extracted from the tissue using TRIzol ${ }^{\circledR}$ Reagent (Plant RNA Purification Reagent for plant tissue) according the manufacturer's instructions (Invitrogen) and genomic DNA was removed using DNase I (TaKara). Then RNA quality was determined by 2100 Bioanalyser (Agilent) and quantified using the ND-2000 (NanoDrop Technologies). Only highquality RNA sample (OD260/280 = 1.8 2.2, OD260/230 $\geq 2.0$, $\mathrm{RIN} \geq 6.5,28 \mathrm{~S}: 18 \mathrm{~S} \geq 1.0,>2 \mu \mathrm{g}$ ) was used to construct sequencing library. (2) RNA-seq transcriptome librariy was prepared following TruSeqTM RNA sample preparation Kit from Illumina (San Diego, CA, United States) using $1 \mu \mathrm{g}$ of total RNA. Shortly, messenger RNA was isolated according to polyA selection method by oligo(dT) beads and then fragmented by fragmentation buffer firstly. Secondly double-stranded cDNA was synthesized using a SuperScript double-stranded cDNA synthesis kit (Invitrogen, CA, United States) with random hexamer primers (Illumina). Then the synthesized cDNA was subjected to end-repair, phosphorylation and " $A$ " base addition according to Illumina's library construction protocol. Libraries were size selected for cDNA target fragments of 200-300 bp on 2\% Low Range Ultra Agarose followed by PCR amplified using Phusion DNA polymerase (NEB) for 15 PCR cycles. After quantified by TBS380, paired-end RNA-seq sequencing library was sequenced with the Illumina HiSeq xten/NovaSeq 6000 sequencer $(2 \times 150 \mathrm{bp}$ read length $)$. The Illumina platform converts the sequenced image signals into textual signals via CASAVA Base Calling and stores them in raw data in fastq format, and performs sequencing-related quality assessments on the raw sequencing data for each sample. (3) The raw paired end reads were trimmed and quality controlled by SeqPrep ${ }^{1}$ and Sickle ${ }^{2}$ with default parameters. Then clean reads were separately aligned to reference genome with orientation mode using TopHat ${ }^{3}$ (Trapnell et al., 2009) software. The mapping criteria of bowtie was as follows: sequencing reads should be uniquely matched to the genome allowing up to 2 mismatches, without insertions or deletions. Then the region of gene were expanded following depths of sites and the operon was obtained. In addition, the whole genome was split into multiple $15 \mathrm{kbp}$ windows that share $5 \mathrm{kbp}$. New transcribed regions were defined as more than 2 consecutive windows without overlapped region of gene, where at least 2 reads mapped per window in the same orientation. (4) To identify DEGs (differential expression genes) between two different samples, the expression level of each transcript was calculated according to the fragments per kilobase of exon per million mapped reads (FRKM) method. RSEM ${ }^{4}$ (Li and Dewey, 2011) was used to quantify gene abundances. R statistical package software EdgeR (Empirical analysis of Digital Gene Expression in $\mathrm{R}^{5}$, Robinson et al., 2010) was utilized for differential expression analysis. In addition, functionalenrichment analysis including GO and Kyoto Encyclopedia of Genes and Genomes (KEGG) were performed to identify which DEGs were significantly enriched in GO terms and metabolic pathways at Bonferroni-corrected $P$-value $\leq 0.05$ compared with

\footnotetext{
${ }^{1}$ https://github.com/jstjohn/SeqPrep

${ }^{2}$ https://github.com/najoshi/sickle

${ }^{3}$ http://tophat.cbcb.umd.edu/, version2.0.0

${ }^{4}$ http://deweylab.biostat.wisc.edu/rsem/

${ }^{5}$ http://www.bioconductor.org/packages/2.12/bioc/html/edgeR.html
} 
the whole-transcriptome background. GO functional enrichment and KEGG pathway analysis were carried out by Goatools ${ }^{6}$ and KOBAS $^{7}$ (Xie et al., 2011). (5) The TopHat-Cufflinks pipeline was used to predict gene isoforms from our RNA-seq data. In TopHat ${ }^{8}$ (Trapnell et al., 2009), the option "min-isoform-fraction" was disabled, instead "coverage-search," "butterfly search," and "microexon-search" were used. The expected fragment length was set to $200 \mathrm{bp}$ and the "small-anchor-fraction" was set to 0.08 , which requires at least 8 bp on each side of an exon junction for our 100-bp RNA-seq data. Cuffcompare was used to compare and merge the reference annotation and the isoform predictions. (6) All the alternative splice events that occurred in our sample were identified by using recently releases program Multivariate Analysis of Transcript Splicing $\left(\mathrm{MATS}^{9}\right.$ ) (Shen et al., 2012). Only the isoforms that were similar to the reference or comprised novel splice junctions were considered, and the splicing differences were detected as exon inclusion, exclusion, alternative 5' AGATCGGAAGAGCACACGTC, 3' AGATCGGAAGAGCGTCGTGT, and intron retention events. The high-quality sequencing data were analyzed on the free online platform of Majorbio I-Sanger Cloud Platform ${ }^{10}$. The transcriptomic data have been deposited into the SRA database under the accession numbers of PRJNA544616 (https://www. ncbi.nlm.nih.gov/sra/PRJNA544616).

\section{Quantitative RT-PCR}

Firstly, a $1 \times 10^{6} \mathrm{CFU} / \mathrm{mL}$ fungal culture was incubated for $4 \mathrm{~h}$ (for adherence) or $24 \mathrm{~h}$ (for biofilms) at $37^{\circ} \mathrm{C}$. The fungal cells were collected through centrifugation for $3 \mathrm{~min}$ at $12700 \mathrm{~g}$, and then total RNA samples were extracted in accordance with the manufacturer's instructions for the MagExtractor-RNA kit (Toyobo, Tokyo, Japan). Extracted total RNA (6 $\mu \mathrm{L})$ was mixed with $2 \mu \mathrm{L}$ of $4 \times$ DNA Master I (containing gDNA remover) and $2 \mu \mathrm{L}$ 5RT-Master Mix II through instant centrifugation at $3000 \mathrm{~g}$, and reverse-transcribed into cDNA as recommended by the instructions of the ReverTra Ace qPCR RT Master Mix with gDNA Remover kit (Toyobo, Tokyo, Japan), with procedures as follows: pre-denature RNA in GeneTest series gene amplifier (BIO-GENER, Hangzhou, China) at $65^{\circ} \mathrm{C}$ for $5 \mathrm{~min}, 4^{\circ} \mathrm{C}$ for $1 \mathrm{~min}$, and then at $37^{\circ} \mathrm{C}$ for $15 \mathrm{~min}, 50^{\circ} \mathrm{C}$ for $5 \mathrm{~min}, 98^{\circ} \mathrm{C}$ for $5 \mathrm{~min}$, and $4^{\circ} \mathrm{C}$ for $1 \mathrm{~min}$ to finally generate cDNA. The prepared cDNA was diluted 10-fold prior to use for semi-quantitative PCR and qRT-PCR. Primers for C. albicans (Table 1) were designed using Primer Premier 5.0 and synthesized by Sangon Biotech. The qRT-PCR mixture $(25 \mu \mathrm{L})$ was freshly prepared containing $12.5 \mu \mathrm{L}$ of SYBR green fluorescent dyes, $1 \mu \mathrm{L}$ of PCR forward primer, $1 \mu \mathrm{L}$ of PCR reverse primer, $0.5 \mu \mathrm{L}$ of cDNA, and $10 \mu \mathrm{L}$ of DEPC treated water. The qRT-PCR process was performed using an ABI7000 fluorescence quantitative PCR system with the following cycles: $95^{\circ} \mathrm{C}$ for $60 \mathrm{~s}$ for pre-denaturation alone with $95^{\circ} \mathrm{C}$ for $15 \mathrm{~s}, 50^{\circ} \mathrm{C}$ for $15 \mathrm{~s}$, and $72^{\circ} \mathrm{C}$ for $45 \mathrm{~s}$ for a total of 40

\footnotetext{
${ }^{6}$ https://github.com/tanghaibao/Goatools

${ }^{7}$ http://kobas.cbi.pku.edu.cn/home.do

${ }^{8}$ http://tophat.cbcb.umd.edu/, version2.0.0

${ }^{9}$ http://rnaseq-mats.sourceforge.net/

${ }^{10}$ www.i-sanger.com
}

cycles. All data were normalized to the housekeeping gene $\beta$-actin as the internal reference gene. The relative target-gene expression was calculated as a fold change of the $2^{-\Delta \Delta C t}$ value, in which $\Delta \mathrm{Ct}=\mathrm{Ct}$ target gene $-\mathrm{Ct}$ internal reference genes, as previously described (Livak and Schmittgen, 2001).

\section{Semi-Quantitative PCR}

The preparation steps for the cDNA are the same as those described previously. The primer sequences used in the semiquantitative PCR are shown in Table 1. The PCR mixture $(25 \mu \mathrm{L})$ was freshly prepared containing $12.5 \mu \mathrm{L}$ of $2 \times$ EasyTaq $^{\circledR}$ PCR SuperMix, $0.5 \mu \mathrm{L}$ of PCR forward primer, $0.5 \mu \mathrm{L}$ of PCR reverse primer, $0.5 \mu \mathrm{L}$ of $\mathrm{cDNA}$, and $11 \mu \mathrm{L}$ of DEPC treated water. PCR conditions were as follows: $94^{\circ} \mathrm{C}$ for $5 \mathrm{~min}, 35 \mathrm{cycles}$ at $94^{\circ} \mathrm{C}$ for $30 \mathrm{~s}, 50^{\circ} \mathrm{C}$ for $30 \mathrm{~s}, 72^{\circ} \mathrm{C}$ for $30 \mathrm{~s}$, with a final extension at $72^{\circ} \mathrm{C}$ for $5 \mathrm{~min}$. The PCR process was performed using a GeneTest series gene amplifier (BIO-GENER, Hangzhou, China). PCR products were analyzed using a $1.5 \%$ agarose gel and compared with a D2000 plus DNA Ladder (Solarbio, Beijing, China). The horizontal electrophoresis conditions were $110 \mathrm{v}, 80 \mathrm{~mA}, 20 \mathrm{~min}$, and the agarose gel was placed into a JY04S-3E imaging analysis system (Junyi, Beijing, China) for gel imaging. The brightness of the PCR products was observed, and it was proportional to the target gene expression.

\section{Detection of cAMP Levels}

Candida albicans cell culture medium $\left(1 \mathrm{~mL} ; 2 \times 10^{6} \mathrm{CFU} / \mathrm{mL}\right)$ was co-incubated with the same volumes of SNH or FLZ in a 6-well flat-bottomed microplate at $37^{\circ} \mathrm{C}$ for $2 \mathrm{~h}$ and $4 \mathrm{~h}$ (for adherence) or $24 \mathrm{~h}$ (for biofilms). The Candida

TABLE 1 | Primers for qRT-PCR.

\begin{tabular}{|c|c|c|}
\hline Oligo Name & Sequence $\left(5^{\prime}\right.$ to $\left.3^{\prime}\right)$ & Length (bp) \\
\hline$\beta$-actin-Forward & ACC GAA GCT CCA ATG AAT CC & 20 \\
\hline$\beta$-actin-Reverse & CCG GTG GTT CTA CCA GAA GAG & 21 \\
\hline ALS1-Forward & GGA TCT GTT ACT GGT GGA GCT GTT G & 25 \\
\hline ALS1-Reverse & ATG TGT TGG TTG AAG GTG AGG ATG AG & 26 \\
\hline ALA1-Forward & GGC TAC GTG TTA CAC ACT GGT & 21 \\
\hline ALA1-Reverse & TCA ACG CCA TCT CCA AGG AC & 20 \\
\hline ALS3-Forward & CAA CTT GGG TTA TTG AAA CAA AAA CA & 26 \\
\hline ALS3-Reverse & AGA AAC AGA AAC CCA AGA ACA ACC T & 25 \\
\hline EAP1-Forward & ATC TAC CTC CTA CAC GAC TGA CAC TG & 26 \\
\hline EAP1-Reverse & TGT ATG AGA ACA AGA ACC GCC ATC AC & 26 \\
\hline RAS1-Forward & GAG GTG GTG GTG TTG GTA & 18 \\
\hline RAS1-Reverse & TTC TTC TTG TCC AGC AGT ATC & 21 \\
\hline EFG1-Forward & ATT GAG ATG TTG CGG CAG GAT AC & 23 \\
\hline EFG1-Reverse & ACT GGA CAG ACA GCA GGA C & 19 \\
\hline HWP1-Forward & ACA GGT AGA CGG TCA AGG & 18 \\
\hline HWP1-Reverse & GGG TAA TCA TCA CAT GGT TC & 20 \\
\hline TEC1-Forward & AGG TTC CCT GGT TTA AGT G & 19 \\
\hline TEC1-Reverse & ACT GGT ATG TGT GGG TGA T & 19 \\
\hline YWP1- Forward & CTG ATA TTC GTA ATG CTG GTA AAG TG & 26 \\
\hline YWP1- Reverse & GGA GTT TCA CCC ATT AAT CTT CTT C & 25 \\
\hline RHD1-Forward & TTA GAG AAA TGT GGC TGT GGT G & 22 \\
\hline RHD1-Reverse & TCA CAT AAC CCT TTA TCA GGC C & 22 \\
\hline
\end{tabular}


cells were scraped using a cell scraper, suspended in medium, and centrifuged for $3 \mathrm{~min}$ at $12700 \mathrm{~g}$. The supernatant was analyzed for cAMP in accordance with the manufacturer's protocol, and the cAMP concentration of each group was examined using a microplate reader (Thermo Labserv K3, Beijing, China) and ELISA kits purchased from RUIXIN Biotech (Quanzhou, China).

\section{In vivo Evaluation of Antifungal Efficacy of SNH Against C. albicans}

Old Galleria mellonella larvae were purchased from Tianjin Huiyude Biological Technology Co., Ltd., each weighing 0.2$0.3 \mathrm{~g}$, and they were approximately $2-3 \mathrm{~cm}$ in length. They were stored in a refrigerator at $4^{\circ} \mathrm{C}$ until use. The larvae were placed on an ultra-clean bench, activated at room temperature for $30 \mathrm{~min}$, and then the in vivo injection experiment was performed.

Preparation of Candida injection: a single colony was chosen on the Sabouraud's agar plate and inoculated into liquid Sabouraud medium, which was placed on a shaker at $220 \mathrm{rpm}$, at $37^{\circ} \mathrm{C}$, for $12 \mathrm{~h}$, and then the cells were collected, the upper medium was removed, and the cells were resuspend in PBS. The cell concentration was adjusted to $8 \times 10^{6} \mathrm{CFU} / \mathrm{mL}, 10 \mu \mathrm{L}$ of Candida solution was injected into the right anterior side of the second section of the stomach and foot. Larvae were inoculated with $8 \times 10^{4}$ yeast cells per $10 \mu \mathrm{L}$ into the hemolymph, as described previously (Bergin et al., 2006; Harding et al., 2013; Manoharan et al., 2017b).

All drugs were dissolved in PBS without any cosolvent to avoid the toxic effects of cosolvents for insects. The drugs were sonicated for a few seconds, and then placed in $\mathrm{a} 75^{\circ} \mathrm{C}$ water bath for $20 \mathrm{~min}$. During this period, the drug solutions were shaken and mixed continuously until the drug was completely dissolved and diluted with PBS to $512 \mu \mathrm{g} / \mathrm{mL}, 256 \mu \mathrm{g} / \mathrm{mL}$, and $128 \mu \mathrm{g} / \mathrm{mL}$ (SNH), and $128 \mu \mathrm{g} / \mathrm{mL}$ and $64 \mu \mathrm{g} / \mathrm{mL}$ (FLZ).

Galleria mellonella larvae $(n=20$ larvae per group) were grouped as follows: PBS group, infection (C. albicans $8 \times 10^{4}$ CFU/larvae) group, infection + SNH $512 \mu \mathrm{g} / \mathrm{mL}$ group, infection + SNH $256 \mu \mathrm{g} / \mathrm{mL}$ group, infection + SNH $128 \mu \mathrm{g} / \mathrm{mL}$ group, infection + FLZ $128 \mu \mathrm{g} / \mathrm{mL}$ group, infection + FLZ $64 \mu \mathrm{g} / \mathrm{mL}$ group, uninfected + SNH $512 \mu \mathrm{g} / \mathrm{mL}$ group, uninfected + SNH $256 \mu \mathrm{g} / \mathrm{mL}$ group, uninfected + SNH $128 \mu \mathrm{g} / \mathrm{mL}$ group, uninfected + FLZ $128 \mu \mathrm{g} / \mathrm{mL}$ group and uninfected + FLZ $64 \mu \mathrm{g} / \mathrm{mL}$ group. Larvae in the infected group were infected with PBS containing C. albicans SC5314 strains $\left(\mathrm{LD}_{50}=8 \times 10^{4} \mathrm{CFU} /\right.$ larvae $)$; drugs groups were administered $1 \mathrm{~h}$ post-infection with $10 \mu \mathrm{L}$ of SNH or FLZ. The PBS group and uninfected group were injected with sterile PBS. The changes in the larvae body were observed every $12 \mathrm{~h}$. If the larvae body was melanized and there was no turning movement, the larvae body was considered to be dead. The larvae were observed continuously for $84 \mathrm{~h}$ and the number of deaths was recorded to determine the survival rate of each group. In view of studies that show that the $\mathrm{LD}_{50}$ of $\mathrm{SNH}$ is $119.14 \mathrm{mg} / \mathrm{kg}$ (Jiang et al., 2006) and the $\mathrm{LD}_{100}$ of SNH is $200 \mathrm{mg} / \mathrm{kg}$ (Lou et al., 2012), our research group selected the dose range $1024-32 \mu \mathrm{g} / \mathrm{mL}$ for $\mathrm{SH}$ in previous experiments (Wang et al., 2019; Zhao et al., 2019).
Therefore, the safety range of $\mathrm{SNH}$ is large, and it has no obvious cytotoxicity.

\section{Statistical Analysis}

All experiments were repeated at least three times. Data represent biological replicates. Data meet the assumptions of the statistical tests described for each Figure. Results are expressed as the mean \pm SD. Differences between experimental groups were assessed for significance using a two-tailed unpaired Student's $t$-test with GraphPad Prism 5 software. The ${ }^{*} p<0.05$, ${ }^{* *} p<0.01$, and ${ }^{* * *} p<0.001$ levels were considered to indicate statistical significance.

\section{RESULTS}

\section{Determination of $\mathrm{MIC}_{80}$ and MFC}

Using a microplate reader, we found (Figure 1A) that the cell growth ratio of the $256 \mu \mathrm{g} / \mathrm{mL} \mathrm{SNH}$ group to the control group was $17.15 \%$; that is, $82.85 \%$ of Candida growth was inhibited within $24 \mathrm{~h}$. The value of the control well was controlled at approximately 0.2 , and compared with the control well, the drug concentration in the lowest concentration well where the OD value decreased by more than $80 \%$ was the $\mathrm{MIC}_{80}$ (the drug concentration when fungal growth was inhibited by $80 \%)$. Therefore, the $\mathrm{MIC}_{80}$ of $\mathrm{SNH}$ in C. albicans SC5314 was determined to be $256 \mu \mathrm{g} / \mathrm{mL}$. The $64 \mu \mathrm{g} / \mathrm{mL}\left(1 / 4 \mathrm{MIC}_{80}\right)$ dose group had a poor fungal inhibitory effect and had no practical clinical significance, and the $1024 \mu \mathrm{g} / \mathrm{mL}\left(4 \mathrm{MIC}_{80}\right)$ dose group had fungal inhibitory effects that were too strong, which does not conform to the principle of using the lowest dose within the effective dose range. Therefore, the $64 \mu \mathrm{g} / \mathrm{mL}$ and $1024 \mu \mathrm{g} / \mathrm{mL}$ dose groups were not investigated further. We observed the effects of $128 \mu \mathrm{g} / \mathrm{mL}\left(1 / 2 \mathrm{MIC}_{80}\right), 256 \mu \mathrm{g} / \mathrm{mL}$ $\left(1 \mathrm{MIC}_{80}\right)$, and $512 \mu \mathrm{g} / \mathrm{mL}\left(2 \mathrm{MIC}_{80}\right) \mathrm{SNH}$, and $128 \mu \mathrm{g} / \mathrm{mL}$ FLZ on the adherence and biofilm formation of $C$. albicans. In addition, through MFC detection, it was found that with $\mathrm{SNH}$ at MIC, $2 \mathrm{MIC}$ and $4 \mathrm{MIC}$ for $24 \mathrm{~h}$ the number of colonies was greater than three (Figure 1B), indicating that SNH has no fungicidal effect on C. albicans SC5314, and only inhibits fungal action.

\section{SNH Inhibits C. albicans Adhesion and Hypha Growth}

Through a CFU plate count (Figure 1C), we found that SNH treatment for $0 \mathrm{~h}$ resulted in no significant difference compared with the control group. After $2 \mathrm{~h}$ of $\mathrm{SNH}$ treatment, the CFU counts in the SNH groups were less than those in the control group, but the difference was not statistically significant. After $4 \mathrm{~h}$ of $\mathrm{SNH}$ treatment, the CFU counts in the $\mathrm{SNH}$ groups were significantly less than those in the control group, and the difference was statistically significant. The $p$-Value for the $\mathrm{SNH} 512 \mu \mathrm{g} / \mathrm{mL}$ group was $<0.001$, the $p$-Value for the $\mathrm{SNH}$ $256 \mu \mathrm{g} / \mathrm{mL}$ group was $<0.01$, and the $p$-Value for the $\mathrm{SNH}$ $128 \mu \mathrm{g} / \mathrm{mL}$ group was $<0.05$. This shows that $\mathrm{SNH}$ exerts the best anti-fungal effect by $4 \mathrm{~h}$ of initial adhesion. In addition, 

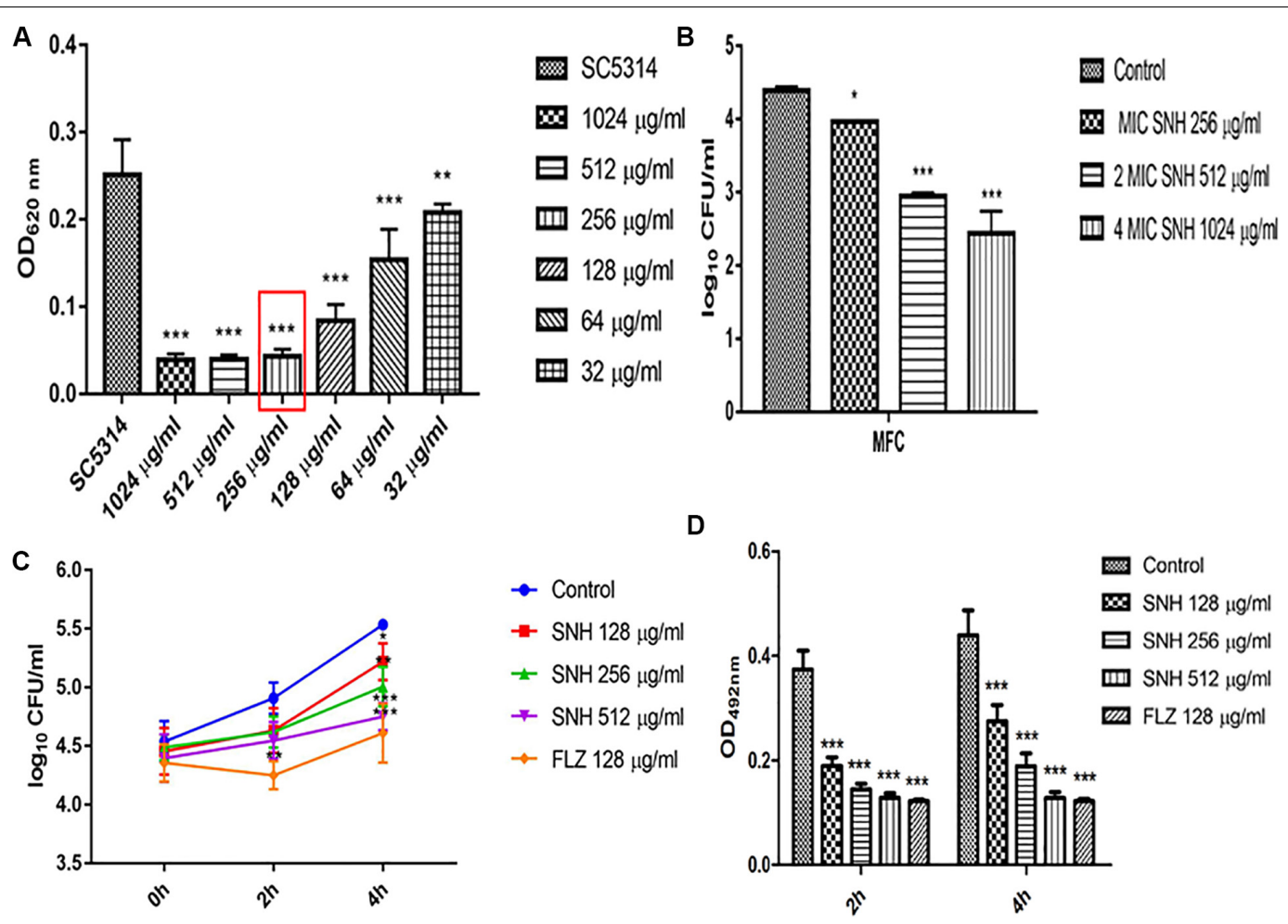

E

\section{Control}

SNH $128 \mu \mathrm{g} / \mathrm{ml}$

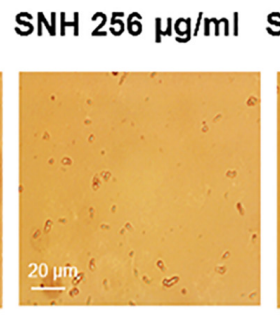

SNH $512 \mu \mathrm{g} / \mathrm{ml}$

$\mathrm{FLZ} 128 \mu \mathrm{g} / \mathrm{ml}$
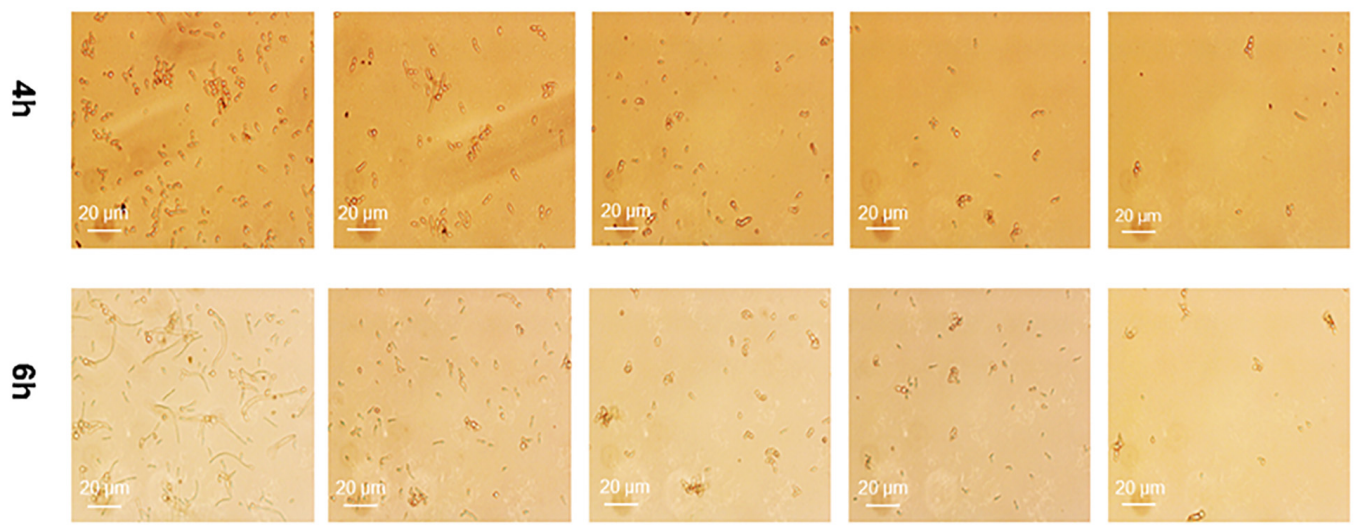

FIGURE 1 | (A) Determination of $\mathrm{MIC}_{80}$ of SNH on C. albicans SC5314 by microdilution method. The drug-free strain-containing medium was set as the control. Data are shown as mean \pm SD. ${ }^{\star \star \star} p<0.001$ and ${ }^{* \star} p<0.01$, compared with the control. (B) Determination of MFC of SNH on C. albicans SC5314 by plate count. The drug-free strain-containing medium was set as the control. Data are shown as mean \pm SD. ${ }^{* *} p<0.001$ and ${ }^{*} p<0.05$, compared with the control. (C) Effect of SNH on CFU of adhesive cells of C. albicans SC5314. The initial adhesive growth curve measurements were taken for the first $4 \mathrm{~h}$. The drug-free strain-containing medium was set as the control. Data are shown as mean \pm SD. ${ }^{*} p<0.05$, compared with the control. (D) Effect of SNH on adherence metabolic activity in C. albicans SC5314 by the XTT reduction assay. The drug-free strain-containing medium was set as the control. Data are shown as mean \pm SD. ${ }^{\star \star *} p<0.001$, compared with the control. (E) Observation of morphological changes of $C$. albicans yeast ( $4 \mathrm{~h})$ and hypha ( $6 \mathrm{~h}$ ) by inverted microscope ( $\times 400)$. The initial inoculum was newly prepared at $2 \times 10^{6} \mathrm{CFU} / \mathrm{mL}$. The drug-free strain-containing medium was set as the control.

through an XTT assay, we found that the addition of SNH to C. albicans after a 2 and $4 \mathrm{~h}$ incubation can significantly reduce adherence activity (Figure 1D) in a concentration-dependent manner. The $p$-Value of the $\mathrm{SNH}$ groups at $2 \mathrm{~h}$ and $4 \mathrm{~h}$ were $<0.001$. Therefore, the results show that $\mathrm{SNH}$ can effectively inhibit the initial adhesion activity of $C$. albicans. The inverted microscope results (Figure 1E) indicate that SNH and FLZ treatment are similar and can effectively reduce cell adhesion in C. albicans when administered for $4 \mathrm{~h}$. In addition, we also found that the control group demonstrated obvious slender hyphae at $6 \mathrm{~h}$, while the hyphae of C. albicans were effectively inhibited after $\mathrm{SNH}$ treatment, whereby only a few yeast-like cells appeared, 
and no obvious hyphae were observed (Figure 1E). This result suggests that $\mathrm{SNH}$ can effectively inhibit the transition of yeast to hyphae in C. albicans, thereby providing the possibility of biofilm inhibition.

\section{SNH Affects the Biofilm Formation of C. albicans}

Through an XTT assay (Figure 2A), we found that at $24 \mathrm{~h}$, compared with the control group, $\mathrm{SNH}$ treatment of $C$. albicans significantly reduced the biofilm $\mathrm{OD}_{492}$ value in a concentrationdependent manner. Each SNH group demonstrated effectively inhibited biofilm metabolic activity $(p<0.05)$. In addition, through the crystal violet quantitative biofilm experiment (Figure 2B), it was also found that $\mathrm{SNH}$ can effectively inhibit biofilm dispersion and biofilm volume $(p<0.001)$. Among the groups, the SNH $512 \mu \mathrm{g} / \mathrm{mL}$ group inhibited biofilm growth by $74.91 \%$, the SNH $256 \mu \mathrm{g} / \mathrm{mL}$ group inhibited biofilm growth by $62.51 \%$, and the SNH $128 \mu \mathrm{g} / \mathrm{mL}$ group inhibited biofilm growth by $40.63 \%$. We also observed the growth and morphological changes in C. albicans biofilms after $\mathrm{SNH}$ treatment through crystal violet staining, CLSM, and SEM (Figures 2D-F). The images showed that the control group demonstrated a large and thick biofilm at $24 \mathrm{~h}$. SNH inhibited the formation of biofilms at $24 \mathrm{~h}$, but single fungal bodies and a small biofilm structure was observed, and so it appears that $\mathrm{SNH}$ inhibits the formation of large biofilm structures. In addition, the CLSM analysis (Figure 2C) also showed that SNH can effectively inhibit biofilm formation $(p<0.001)$. In summary, $\mathrm{SNH}$ has the potential to inhibit C. albicans biofilms.

\section{SNH Inhibits Biofilms of Several Clinical Strains of C. albicans}

To further investigate the potential of $\mathrm{SNH}$ against C. albicans biofilms, we selected four clinical strains of C. albicans, Z1402, Z1407, Z103, and Z3044 for these experiments. First, the $M_{1 C_{80}}$ of $\mathrm{SNH}$ in clinical strains of $C$. albicans was detected through a 96-well microdilution method. Interestingly, the $\mathrm{MIC}_{80}$ of $\mathrm{SNH}$ in clinical strains was better than that in standard strains, whereby the $\mathrm{MIC}_{80}$ of $\mathrm{SNH}$ in clinical strains decreased 1-2fold compared with that in standard strains. The $\mathrm{MIC}_{80}$ of SNH in $\mathrm{Z103}$ was $64 \mu \mathrm{g} / \mathrm{mL}$ (Figure 3C) and the $\mathrm{MIC}_{80}$ of $\mathrm{SNH}$ in $\mathrm{Z} 3044$ was $128 \mu \mathrm{g} / \mathrm{mL}$ (Figure 3D). Moreover, the $\mathrm{MIC}_{80}$ of SNH in both Z1402 and Z1407 was $256 \mu \mathrm{g} / \mathrm{mL}$ (Figures 3A,B), which was the same as that in SC5314. We further tested the biofilm dispersion and biofilm quantity in four clinical strains treated using $\mathrm{SNH}$ through a crystal violet quantitative biofilm experiment. Each clinical strain was established in 2 MIC SNH, MIC SNH and 1/2 MIC SNH groups. It was found that the $\mathrm{OD}_{570 \mathrm{~nm}}$ of each $\mathrm{SNH}$ group was significantly lower than that of the control group $(p<0.01)$. The $\mathrm{SNH}$ $512 \mu \mathrm{g} / \mathrm{mL}$ group demonstrated $38.61 \%$ inhibition of biofilm growth of Z1402, the SNH $256 \mu \mathrm{g} / \mathrm{mL}$ group demonstrated $37.24 \%$ inhibition of biofilm growth of Z1402, and the SNH $128 \mu \mathrm{g} / \mathrm{mL}$ group demonstrated $25.06 \%$ inhibition of biofilm growth of Z1402 (Figure 3E). The SNH $512 \mu \mathrm{g} / \mathrm{mL}$ group demonstrated $53.08 \%$ inhibition of biofilm growth of Z1407, the SNH $256 \mu \mathrm{g} / \mathrm{mL}$ group demonstrated 51.41\% inhibition of biofilm growth of Z1407, and the SNH $128 \mu \mathrm{g} / \mathrm{mL}$ group demonstrated $45.73 \%$ inhibition of biofilm growth of Z1407 (Figure 3F). The SNH $512 \mu \mathrm{g} / \mathrm{mL}$ group demonstrated $51.38 \%$ inhibition of biofilm growth of Z103, the SNH $256 \mu \mathrm{g} / \mathrm{mL}$ group demonstrated $49.52 \%$ inhibition of biofilm growth of Z103, and the SNH $128 \mu \mathrm{g} / \mathrm{mL}$ group demonstrated $42.03 \%$ inhibition of biofilm growth of Z103 (Figure 3G). The SNH $512 \mu \mathrm{g} / \mathrm{mL}$ group demonstrated $56.32 \%$ inhibition of biofilm growth of Z3044, the SNH $256 \mu \mathrm{g} / \mathrm{mL}$ group demonstrated $46.51 \%$ inhibition of biofilm growth of Z3044, and the SNH $128 \mu \mathrm{g} / \mathrm{mL}$ group demonstrated 33.49\% inhibition of biofilm growth of Z3044 (Figure 3H). We also observed biofilm growth and morphological changes in four clinical C. albicans strains after SNH treatment through crystal violet staining (Figure 3I). The images show that the clinical strain control groups all demonstrated large and thick biofilms at $24 \mathrm{~h}$. While $\mathrm{SNH}$ can inhibit biofilm formation at $24 \mathrm{~h}$, small biofilm structures could be seen, and therefore it could be considered that $\mathrm{SNH}$ inhibits the formation of large biofilm structures of C. albicans clinical strains. In terms of the ability of $2 \mathrm{MIC} \mathrm{SNH}$ to inhibit biofilms, $\mathrm{SNH}$ at this concentration can reduce the biofilm quantities of Z3044, Z1407 and Z103 by more than $50 \%$, but has a poor ability to inhibit the biofilms of Z1402. In terms of the ability of $1 \mathrm{MIC} \mathrm{SNH}$ to inhibit biofilms, $\mathrm{SNH}$ at this concentration can inhibit biofilms by more than $50 \%$ for Z1407. In terms of the ability of $1 / 2$ MIC SNH to inhibit biofilms, $\mathrm{SNH}$ inhibition of the biofilms of clinical strains was weakened, and no group with more than 50\% biofilm inhibition was observed. In general, the ability of SNH to inhibit the biofilms of $C$. albicans clinical strains was in the order: Z1407 > Z103 > Z3044 > Z1402.

\section{SNH Combined With Various Categories of Antifungal Against C. albicans Biofilm}

Here, we investigated four antifungals, FLZ, BBR, CAS, and ITZ, combined with SNH to observe their ability to inhibit C. albicans SC5314 biofilms. First, we tested the $\mathrm{MIC}_{80}$ of the four antifungal drugs against $C$. albicans SC5314 through a microdilution method in 96-well plates, and then tested the $\mathrm{MIC}_{80}$ of the four antifungal drugs combined with $\mathrm{SNH}$ using a checkerboard microdilution method. The results are shown in Table 2. It was found that the FICI of $\mathrm{SNH}$ combined with FLZ, BBR, CAS, or ITZ was $0.27,0.50,0.27$, and 0.50 , respectively. These FICI values were all $\leq 0.05$, which indicated that $\mathrm{SNH}$ had synergistic effects with these four antifungals. We further investigated the effect of $\mathrm{SNH}$ combined with the four antifungals against $C$. albicans biofilms through CLSM (Figure 4F), and analyzed the AOD value of the fluorescence images (Figures 4A-E). Here, we investigated the drugs alone and in combination with a 1 MIC dose for the experiments. The results showed that the four antifungals alone had antibiofilm abilities, and minimal biofilm growth and yeast cells could be seen. However, when the four antifungals were combined with $\mathrm{SNH}$, their anti-biofilm capabilities were strengthened, and compared with the control group, large-scale hyphal 

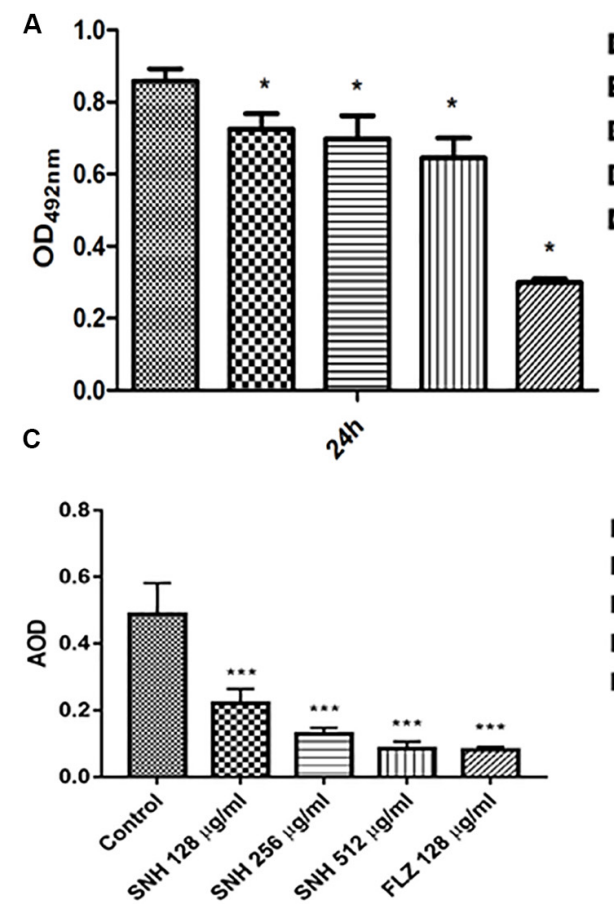

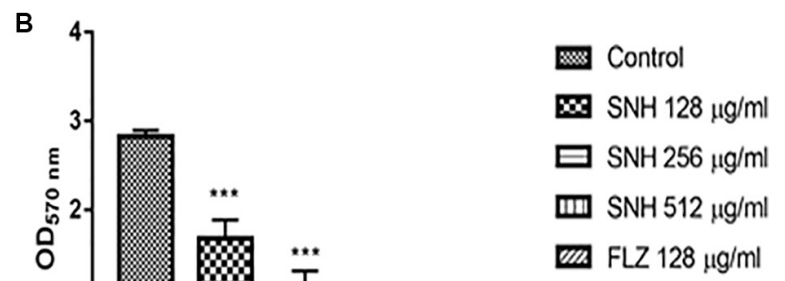

Control

$\infty \mathrm{SNH} 128 \mu \mathrm{g} / \mathrm{m}$

ㄷNH $256 \mu \mathrm{g} / \mathrm{ml}$

미 SNH $512 \mu \mathrm{g} / \mathrm{ml}$

m FLZ $128 \mu \mathrm{g} / \mathrm{ml}$
D

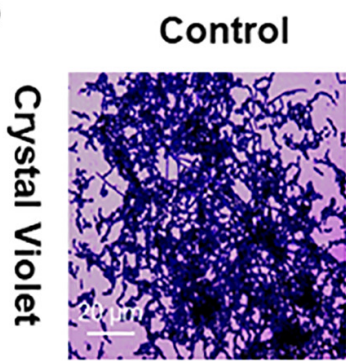

E

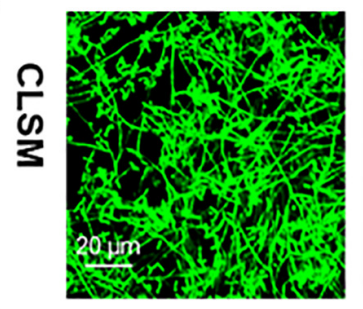

$\mathbf{F}$

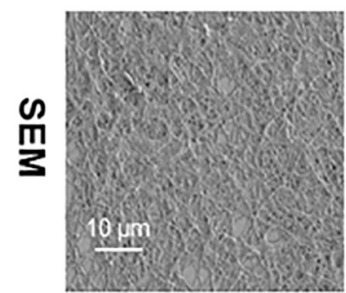

$\mathrm{SNH} 128 \mu \mathrm{g} / \mathrm{ml}$ SNH $256 \mu \mathrm{g} / \mathrm{ml}$
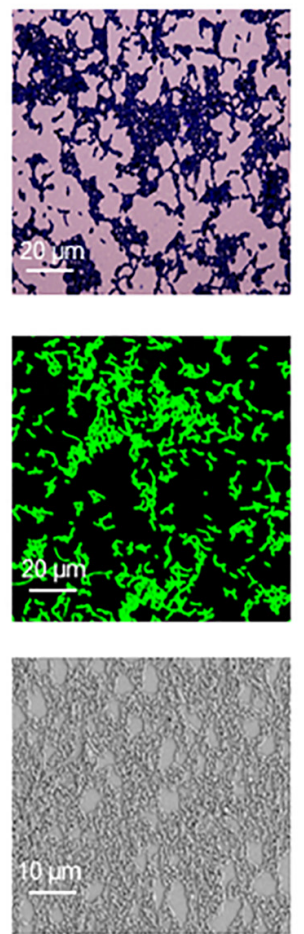
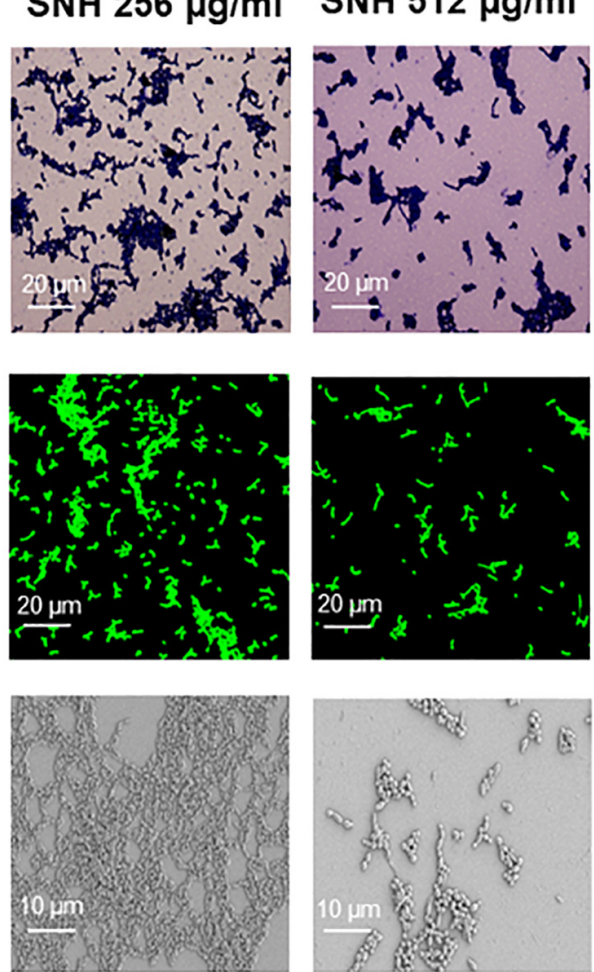
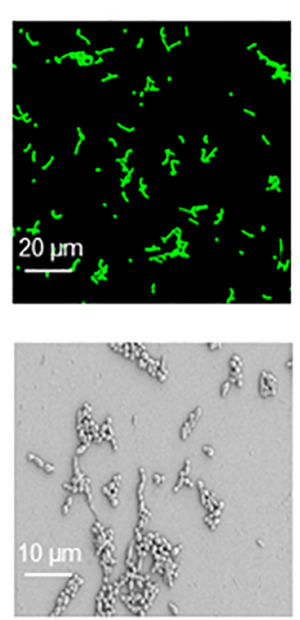

$\mathrm{FLZ} 128 \mu \mathrm{g} / \mathrm{ml}$
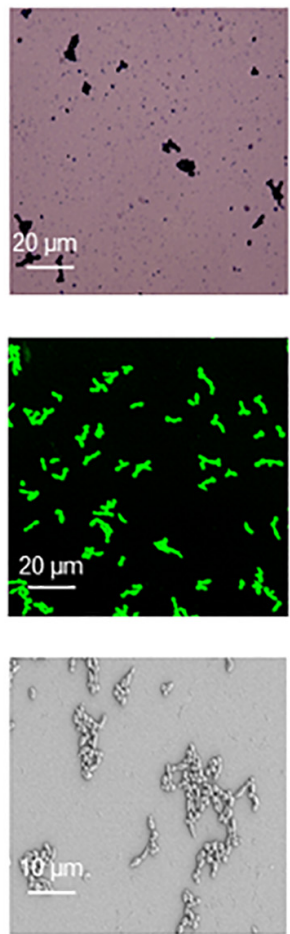

FIGURE 2 | (A) Effect of SNH on biofilm metabolic activity in C. albicans SC5314 by the XTT reduction assay. The drug-free strain-containing medium was set as the control. Data are shown as mean \pm SD. ${ }^{*} p<0.05$, compared with the control. (B) Quantitative determination of C. albicans SC5314 biofilm by crystal violet. The drug-free strain-containing medium was set as the control. Data are shown as mean \pm SD. ${ }^{\star \star \star} p<0.001$, compared with the control. (C) Analyze the AOD (AOD) of CLSM fluorescent C. albicans SC5314 biofilm by Image J. The drug-free strain-containing medium was set as the control. Data are shown as mean \pm SD.

${ }^{* \star *} p<0.001$, compared with the control. (D) Crystal Violet Staining of C. albicans SC5314 biofilm by optical microscope ( $\left.\times 400\right)$. (E) Observation of morphological changes of $C$. albicans SC5314 biofilm by CLSM ( $\times 400)$. (F) Observation of morphological changes of $C$. albicans SC5314 biofilm by SEM ( $\times 500)$. The initial inoculum was newly prepared at $2 \times 10^{6} \mathrm{CFU} / \mathrm{mL}$. The drug-free strain-containing medium was set as the control. 


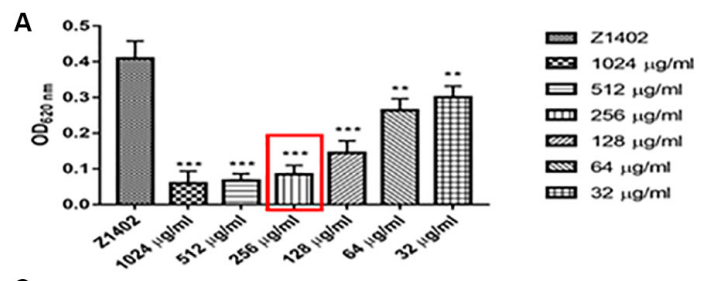

C
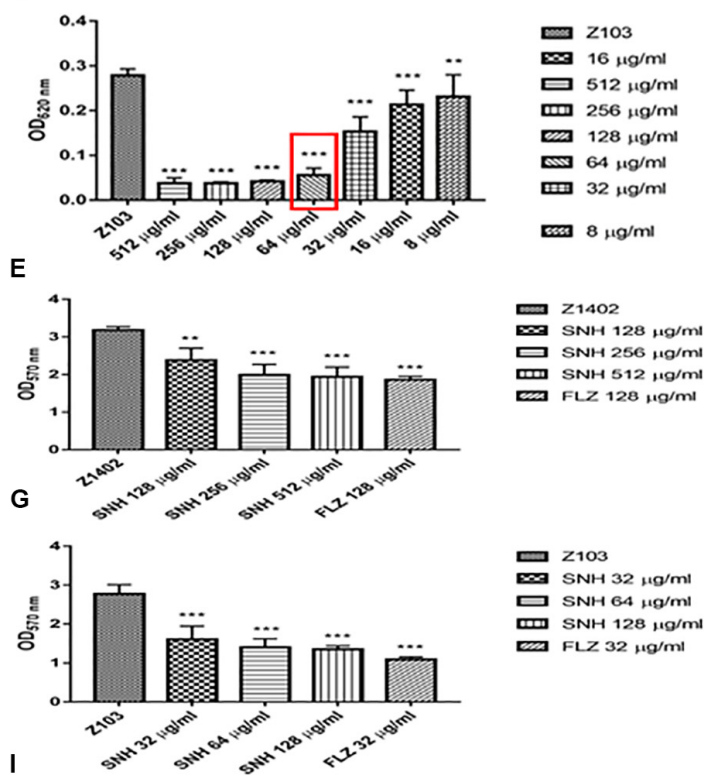

口 SNH $64 \mu \mathrm{\mu g} / \mathrm{ml}$

다. SNH $128 \mu \mathrm{g} / \mathrm{m}$

FLZ $32 \mu g / m$
B
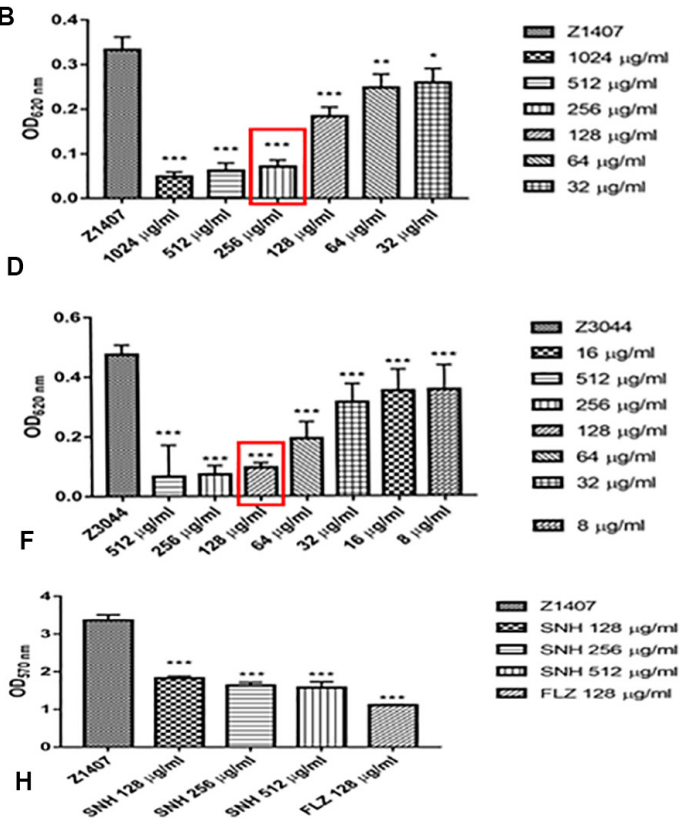

피 21407

SNH $128 \mu \mathrm{g} / \mathrm{mt}$

D SNH $256 \mu \mathrm{g} / \mathrm{mt}$

[ᄄ] SNH $512 \mu \mathrm{g} / \mathrm{m}$

ced $F L Z 128 \mu \mathrm{g} / \mathrm{ml}$

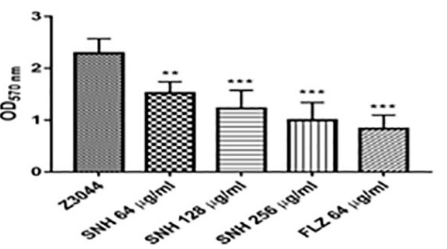

Z3044

SNH $64 \mu \mathrm{g} / \mathrm{mt}$

S SNH $128 \mu \mathrm{g} / \mathrm{ml}$

[m SNH $256 \mu \mathrm{g} / \mathrm{mt}$
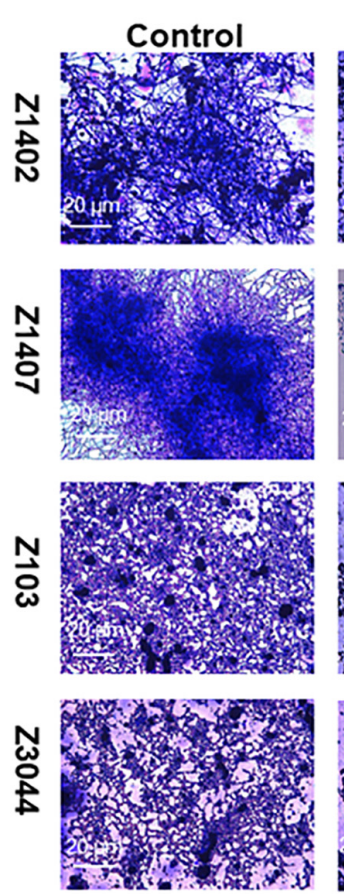

1/2MIC SNH
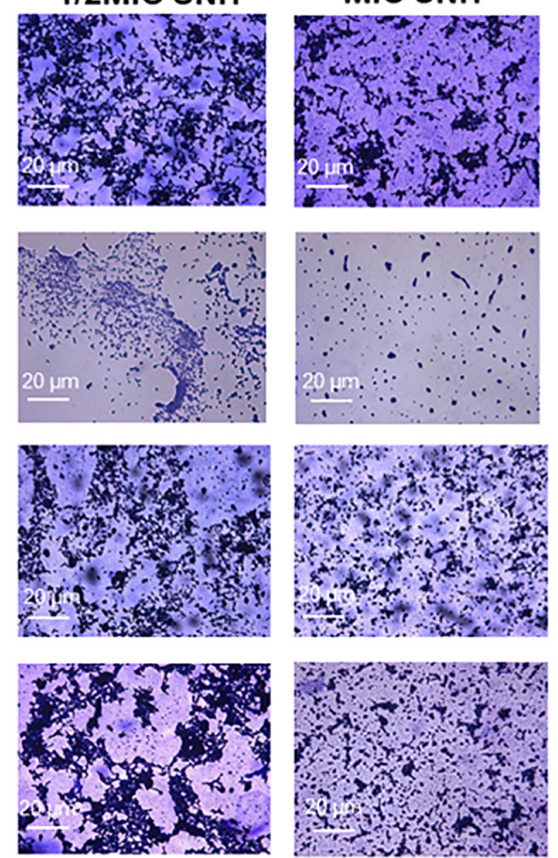

MIC SNH
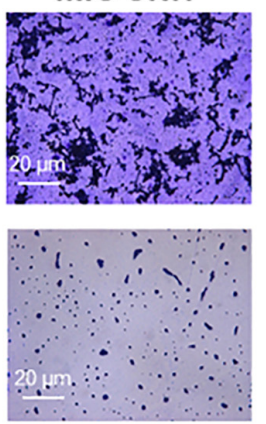

2MIC SNH
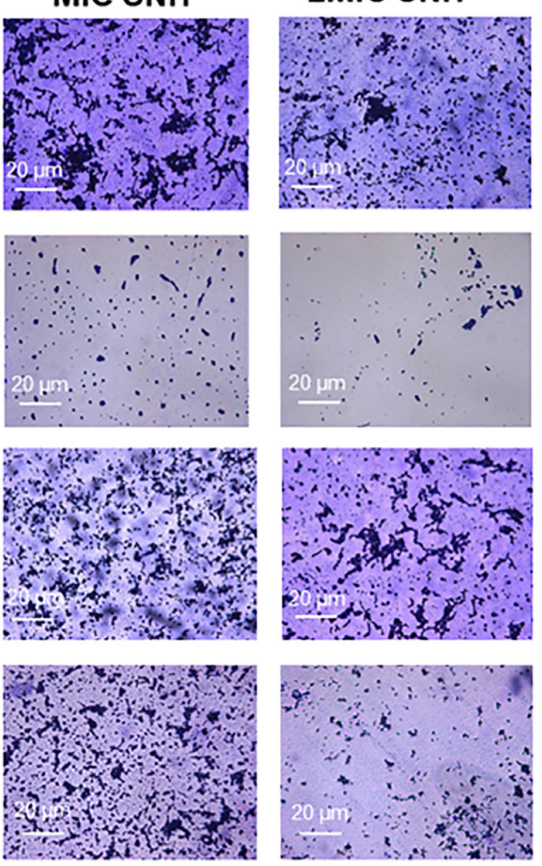
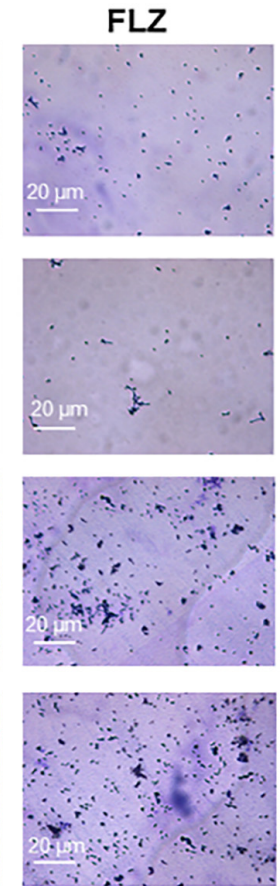

FIGURE 3 | (A-D) Determination of $\mathrm{MIC}_{80}$ of SNH on C. albicans Z1402, Z1407, Z103, and Z3044 by microdilution method, respectively. The drug-free strain-containing medium was set as the control. Data are shown as mean $\pm \mathrm{SD}$. ${ }^{\star \star \star} p<0.001,{ }^{\star \star} p<0.01$, and ${ }^{\star} p<0.05$, compared with the control. (E-H) Quantitative determination of $C$. albicans Z1402, Z1407, Z103 and Z3044 biofilm by crystal violet, respectively. The drug-free strain-containing medium was set as the control. Data are shown as mean \pm SD. ${ }^{* \star *} p<0.001$ and ${ }^{* *} p<0.01$, compared with the control. (I) Crystal Violet Staining of C. albicans Z1402, Z1407, Z103, and Z3044 biofilm by optical microscope $(\times 400)$, respectively. The initial inoculum was newly prepared at $2 \times 10^{6} \mathrm{CFU} / \mathrm{mL}$. The drug-free strain-containing medium was set as the control. 
TABLE 2 | Interaction of SNH and antifungals against C. albicans SC5314 by $\mathrm{MIC}_{80}$ of checkerboard microdilution assay.

\begin{tabular}{lcccc}
\hline & $\begin{array}{c}\mathbf{M I C}_{\mathbf{8 0}}(\boldsymbol{\mu} \mathbf{g} / \mathbf{m l}) \\
\text { alone }\end{array}$ & $\begin{array}{c}\mathbf{M I C}_{\mathbf{8 0}}(\boldsymbol{\mu} \mathbf{g} / \mathbf{m l}) \\
\text { in combination }\end{array}$ & $\begin{array}{c}\text { FIC index for } \\
\text { combination }\end{array}$ & $\begin{array}{c}\text { Mode of } \\
\text { interaction }\end{array}$ \\
\hline SNH/FLZ & $256 / 1$ & $4 / 0.25$ & 0.27 & Syn \\
SNH/BBR & $256 / 16$ & $64 / 4$ & 0.50 & Syn \\
SNH/CAS & $256 / 0.25$ & $1 / 0.125$ & 0.50 & Syn \\
SNH/ITZ & $256 / 8$ & $4 / 2$ & 0.27 & Syn
\end{tabular}

SNH, Sodium new houttuyfonate; FLZ, Fluconazole; BBR, Berberine chloride; CAS, Caspofungin; ITZ, Itraconazole; Syn, Synergism.

structures were completely inhibited, and only single yeastlike cells were observed. Moreover, compared with the control group, the anti-biofilm activity observed following treatment with $\mathrm{SNH}$ combined with the four antifungals was significantly enhanced $(p<0.01)$.

\section{SNH Affects the Transcriptome of C. albicans}

The results described above indicate that SNH can effectively inhibit adhesion and biofilm formation in C. albicans. To elucidate the underlying mechanism, we examined the transcriptomic changes in C. albicans under SNH treatment. As shown in Figure 5A, the total transcriptomes of the blank control group and the $256 \mu \mathrm{g} / \mathrm{mL} \mathrm{SNH}$ group are basically consistent. As shown in Figure 5B, 5711 genes overlap in the two groups, with 55 and 107 genes uniquely expressed in the Control and $\mathrm{SNH}$ treatment groups, respectively. As shown in Figures 5C,D, we found that the expression levels in the blank control group and the $256 \mu \mathrm{g} / \mathrm{mL}$ SNH group were significantly clustered in two groups, while the blank control group and the $256 \mu \mathrm{g} / \mathrm{mL} \mathrm{SNH}$ group had high intra-group correlation. As shown in the volcano map in Supplementary Figure S1, a total of 5873 genes are assembled in the two groups. Compared with the control group, the expression of 611 genes, including 361 down-regulated and 250 up-regulated genes, changed significantly in the $\mathrm{SNH}$ group with fold changes $>2$ and a $p$-Value $<0.05$ (Supplementary Figure S1).

To gain insights into the biological pathways related to the 611 genes, hierarchical clustering (Supplementary Figure S2) of these genes was performed using Matlab to group the data into those genes increasing and decreasing in abundance following SNH treatment. GO enrichment results (Figures 5E,F) indicate that the genes generally down-regulated in $\mathrm{SNH}$ treatment are enriched in pathways associated with biological processes including regulation of biological process, growth, detoxification, response to stimulus, cellular processes, biological regulation, biological adhesion, cell aggregation, and cellular component biosynthesis including cell, cell part, membrane, membrane part and extracellular region, and molecular function including binding, catalytic activity and antioxidant activity. As shown in Supplementary Table S1, SNH can significantly down-regulate the expression of several genes, such as RAS1, ALS3, and HWP1, which are key to the pathogenesis of $C$. albicans. The three genes are involved in biological adhesion, cell aggregation and positive regulation of biological processes and also members of the Ras1-cAMP-Efg1 pathway.

\section{SNH Affects the Expression of Biofilm Related Genes and cAMP Production of the Ras1-cAMP-Efg1 Pathway}

To verify the transcriptome results described above, we examined several genes related to adhesion and biofilms, especially those related to the Ras1-cAMP-Efg1 pathway through the semiquantitative PCR and qRT-PCR methods. In accordance with the transcriptome data, the expression of ALS1, ALA1, ALS3, EAP1, RAS1, EFG1, HWP1, and TEC1 in this pathway are downregulated after $\mathrm{SNH}$ treatment in a dose dependent manner (Figures $6 \mathbf{A}-\mathbf{D}$ ) and the expression of $Y W P 1$ and $R H D 1$ are up-regulated after SNH treatment in a dose dependent manner (Figure 6E), which could explain the defects in adhesion, transition from yeast to hyphae and biofilm formation of C. albicans under SNH treatment. Among these, ALS1 and ALA1 are involved in the initial adhesion of C. albicans, and ALS3 and EAP1 are involved in the formation of $C$. albicans biofilms. Compared with the control group, $\mathrm{SNH}$ treatment significantly reduced the expression levels of the adhesion-related genes, $A L A 1$ and ALS1 (Figure 6A). The ALA1 gene in the $\mathrm{SNH}$ 512,256 , and $128 \mu \mathrm{g} / \mathrm{mL}$ groups was down-regulated by 1.91 fold, 1.65-fold, and 1.39-fold, respectively, and the ALS1 gene in the SNH 512, 256, and $128 \mu \mathrm{g} / \mathrm{mL}$ groups was down-regulated by 1.65 -fold, 1.39-fold, and 1.16-fold, respectively. Moreover, $\mathrm{SNH}$ reduced the expression levels of the biofilm-related genes $A L S 3$ and EAP1 (Figure 6B); specifically, the ALS3 gene in the SNH 512, 256, and $128 \mu \mathrm{g} / \mathrm{mL}$ groups was down-regulated by 2.85-fold, 2.28-fold, and 1.37-fold, respectively, and the EAP1 gene in the $\mathrm{SNH} 512,256$, and $128 \mu \mathrm{g} / \mathrm{mL}$ groups was downregulated by 2.24 -fold, 1.54 -fold, and 1.18 -fold, respectively. In addition, down-regulated the expression levels of the Ras1cAMP-Efg1 pathway- related genes, RAS1, EFG1, TEC1, and HWP1 (Figures 6C,D). Specifically, the RAS1 gene in the SNH 512,256 , and $128 \mu \mathrm{g} / \mathrm{mL}$ groups was down-regulated by 5.36fold, 2.64-fold, and 1.71-fold, respectively, and the EFG1 gene in the SNH 512, 256, and $128 \mu \mathrm{g} / \mathrm{mL}$ groups was down-regulated by 1.83 -fold, 1.38 -fold, and 1.24-fold, respectively. The TEC1 gene in the $\mathrm{SNH} 512,256$, and $128 \mu \mathrm{g} / \mathrm{mL}$ groups was downregulated by 3.35 -fold, 1.90 -fold, and 1.52 -fold, respectively, and the HWP1 gene in the SNH 512, 256, and $128 \mu \mathrm{g} / \mathrm{mL}$ groups was down-regulated by 3.55 -fold, 1.72-fold, and 1.39fold, respectively. The YWP1 and RHD1 genes play a negative regulatory role in the adhesion of yeast-like cells, and the adhesion of biofilms formed by YWP1- or RHD1-deficient strains is enhanced (Figure 6E). The YWP1 gene in the SNH 512, 256, and $128 \mu \mathrm{g} / \mathrm{mL}$ groups was up-regulated by 8.90 -fold, 2.18fold, and 1.93-fold, respectively, and the RHD1 gene in the SNH 512,256 , and $128 \mu \mathrm{g} / \mathrm{mL}$ groups was up-regulated by 3.83 -fold, 1.34-fold, and 1.10-fold, respectively.

To further explore the effects of SNH in the Ras1-cAMPEfg1 pathway, we determined the production of cAMP in C. albicans treated with $\mathrm{SNH}$ at $4 \mathrm{~h}$ and $24 \mathrm{~h}$ after drug treatment. The results (Figure 6F) show that $\mathrm{SNH}$ can significantly 

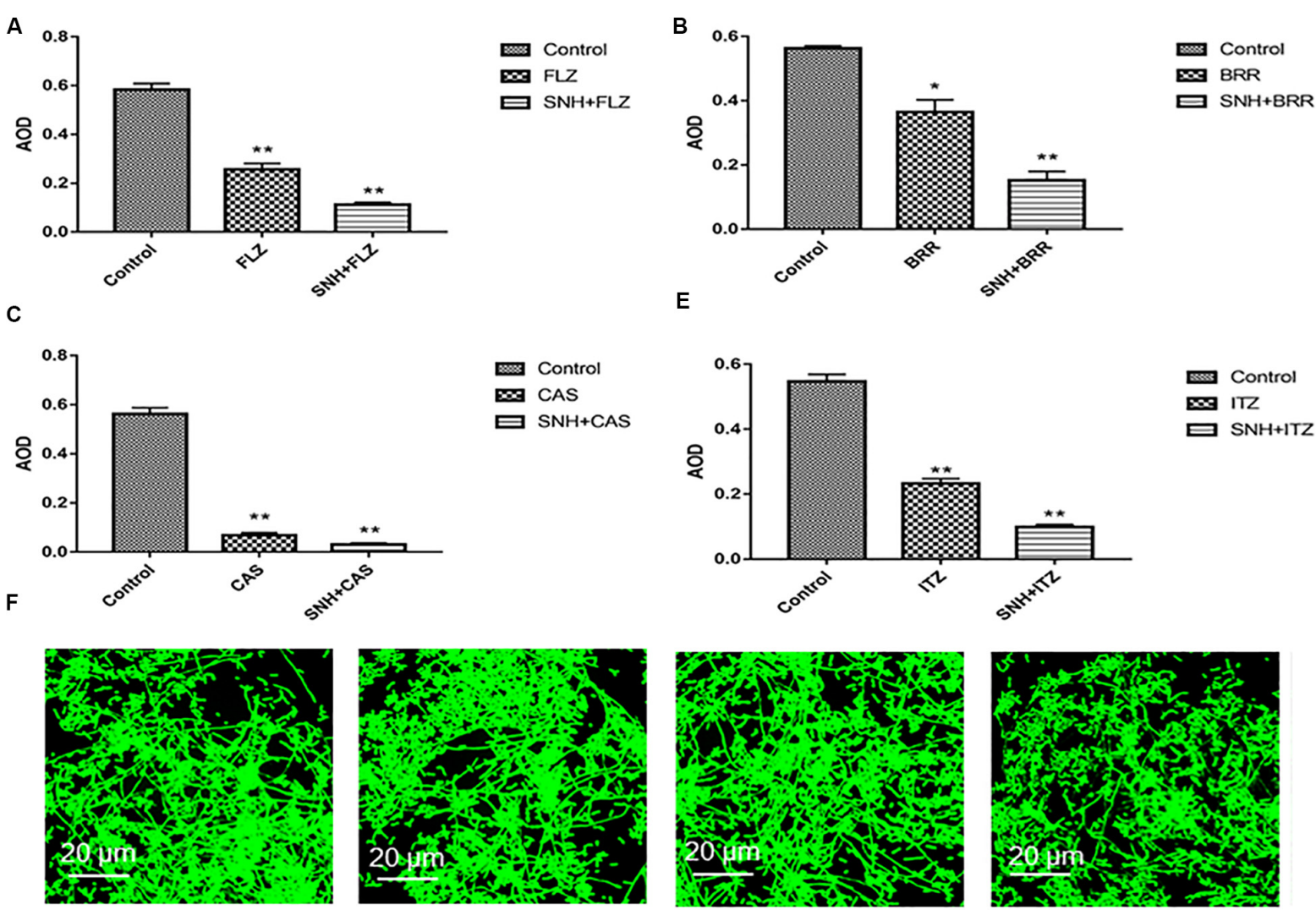

Control

$\infty$ ITZ

曰 $\mathrm{SNH}+\mathrm{ITZ}$

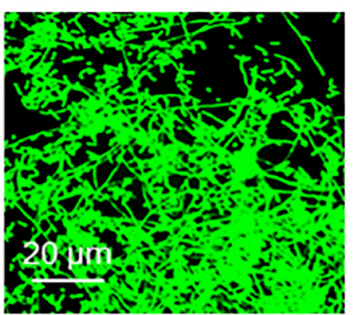

Control

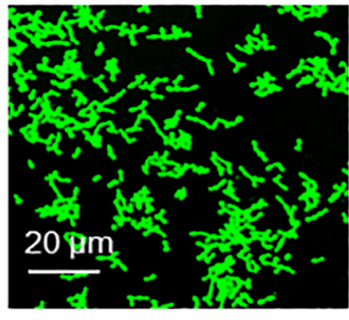

FLZ

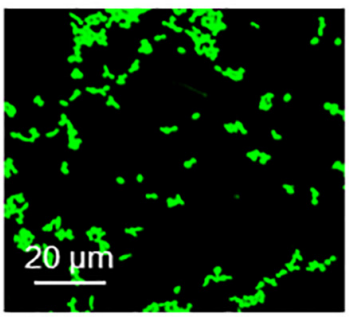

SNH+FLZ

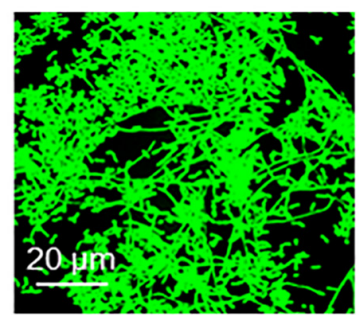

Control

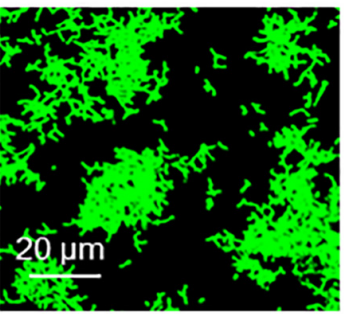

BBR

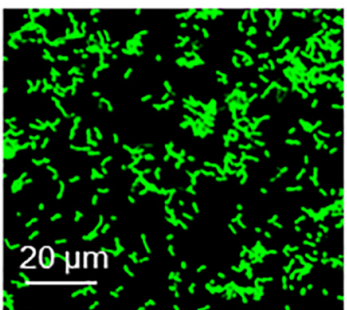

SNH+BBR

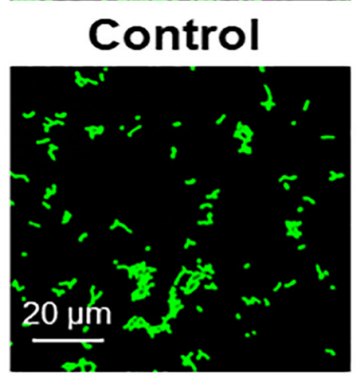

CAS

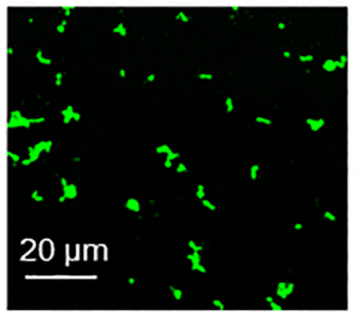

$\mathrm{SNH}+\mathrm{CAS}$

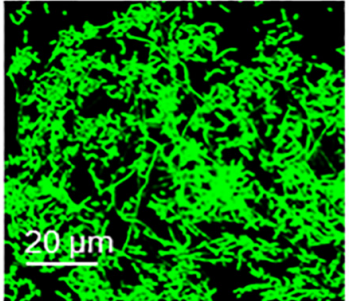

\section{Control}

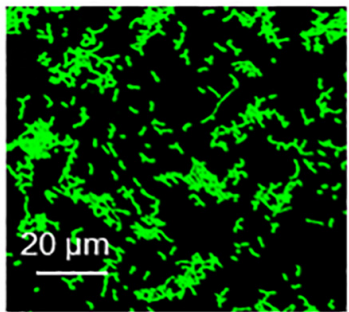

ITZ

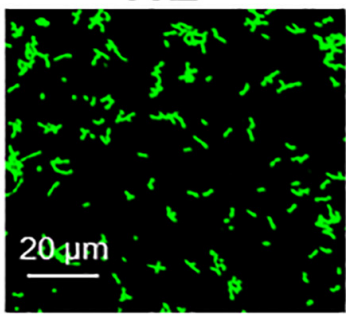

SNH+ITZ

FIGURE 4 | (A-E) Analyze the average optical density (AOD) of SNH and FLZ, BBR, CAS, ITZ on C. albicans SC5314 biofilm by Image J, respectively. The drug-free strain-containing medium was set as the control. Data are shown as mean $\pm \mathrm{SD}$. ${ }^{* *} p<0.01$ and ${ }^{*} p<0.05$, compared with the control. (F) Observation of morphological changes of SNH and FLZ, BBR, CAS, ITZ on C. albicans SC5314 biofilm by CLSM ( $\times 400)$, respectively. The initial inoculum was newly prepared at $2 \times 10^{6} \mathrm{CFU} / \mathrm{mL}$. The drug-free strain-containing medium was set as the control.

reduce the production of cAMP both at $4 \mathrm{~h}$ and $24 \mathrm{~h}$ in a dose-dependent manner. The positive control, FLZ, also significantly inhibited the production of cAMP in C. albicans.
Therefore, our results indicate that SNH can significantly reduce the production of cAMP which is the key messenger molecule of the Ras1-cAMP-Efg1 pathway in C. albicans. 
A

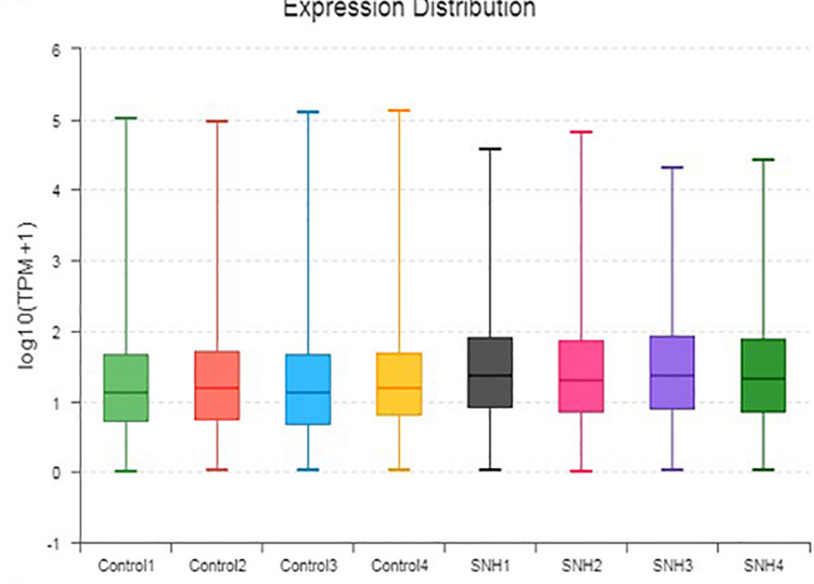

C

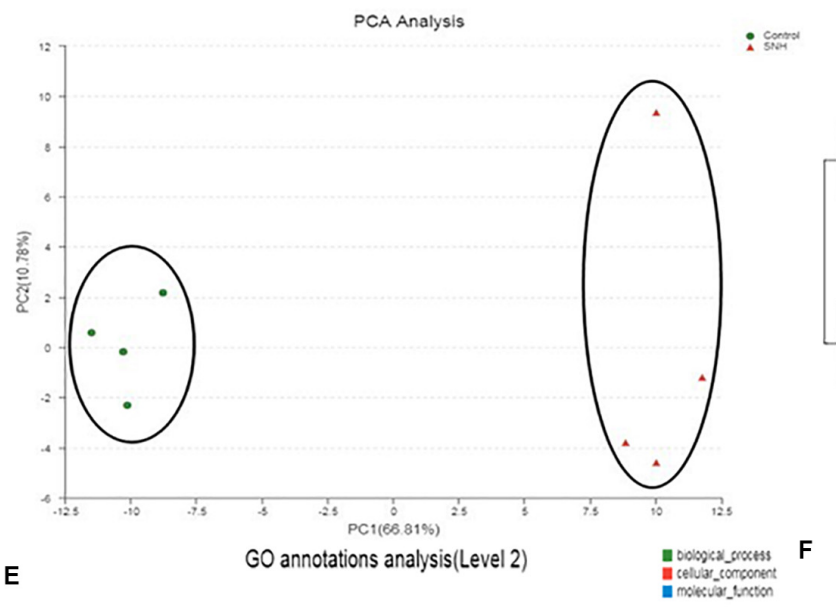

B
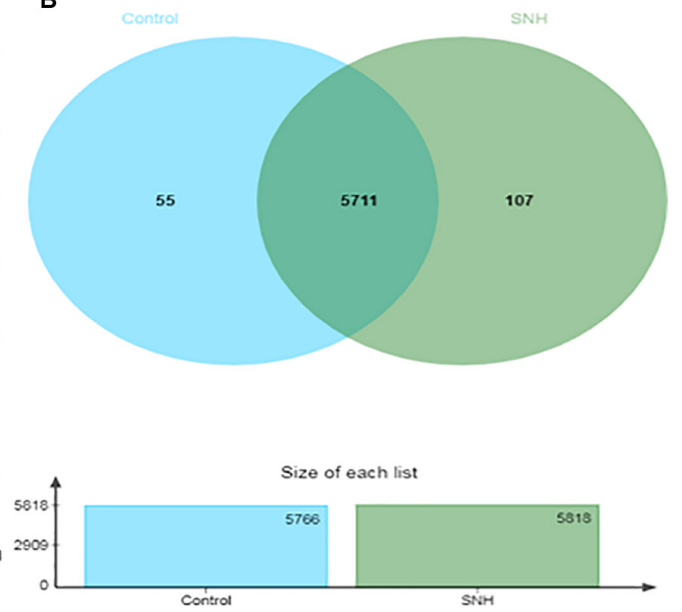

D Correlation between samples

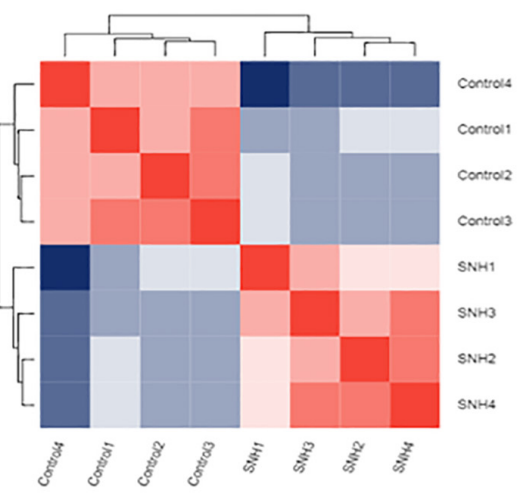

GO enrichment analysis(Control_vs_SNH_G)
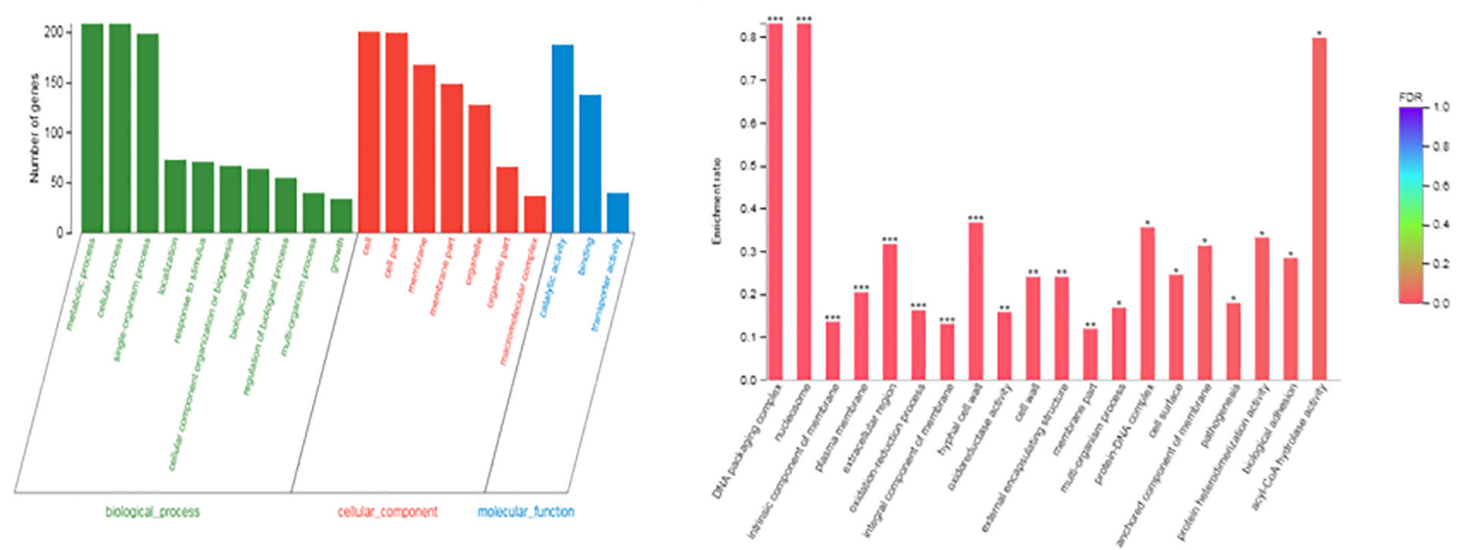

FIGURE 5 | Effect of SNH on the transcriptome of C. albicans SC5314. (A) The abscissa is the sample name and the ordinate is $\log _{10}$ (TPM + 1). Each color in the figure represents a sample, and the horizontal line in the figure indicates the median of gene expression in the sample. (B) Venn diagram of the number of genes in the Control and SNH treatments, respectively. (C) The right and lower sides of the figure are sample names, and the left and upper sides are sample clustering, and the squares of different colors represent the correlation between the two samples in the principle component analysis (PCA). (D) After the sample is analyzed by dimensionality reduction, there are relative coordinate points on the principal component. The distance between each sample point represents the distance of the sample. The closer the distance is, the higher the similarity between samples. The horizontal axis represents the contribution of principal component 1 (PC1) to the differentiated samples in the two-dimensional map, and the vertical axis represents the contribution of principal component 2 (PC2) to the differentiated samples in the two-dimensional map. (E) The abscissa in the figure represents the secondary classification term of GO, the left ordinate indicates the percentage of genes or transcripts contained in the secondary classification, and the right ordinate indicates the genetic/transcription of the secondary classification. (F) The abscissa indicates the GO term, and the ordinate indicates the enrichment rate refers to the ratio of the number of genes/samples enriched in the GO term to the number of the annotation gene/background number. The color indicates the significance of the enrichment, and the redder the default color indicates that the GO term is significantly more enriched, with the FDR $<0.001$ mark being ${ }^{\star \star \star}$, the FDR $<0.01$ mark being ${ }^{\star *}$, and the FDR $<0.05$ mark being *. 
A
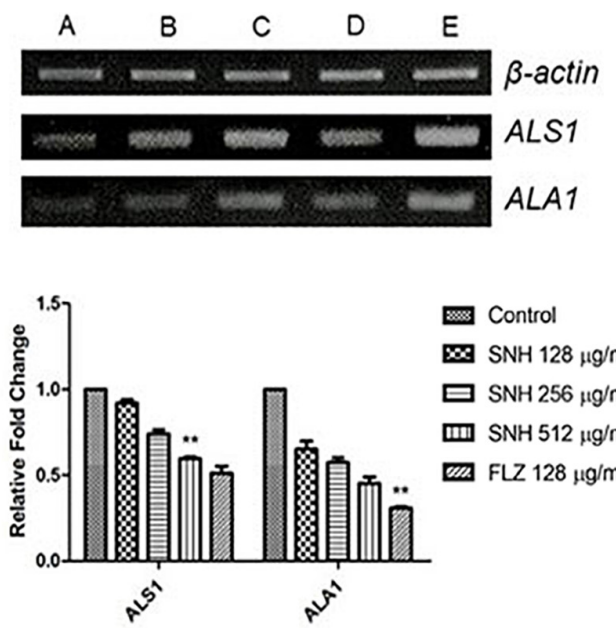

C
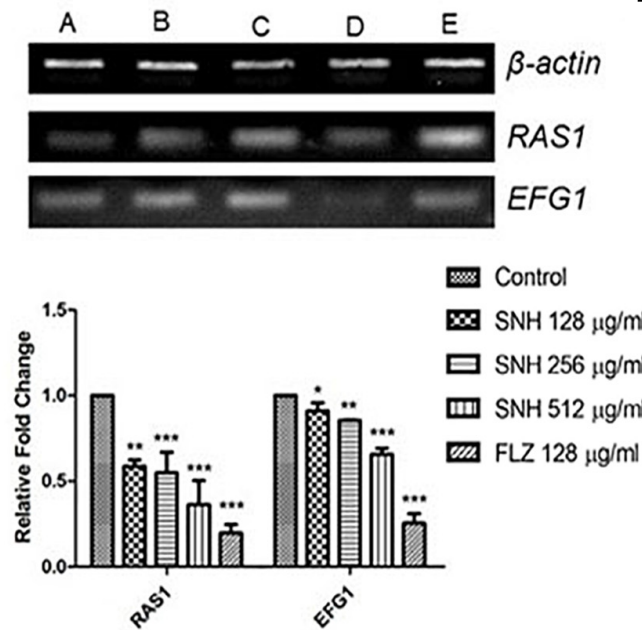

E
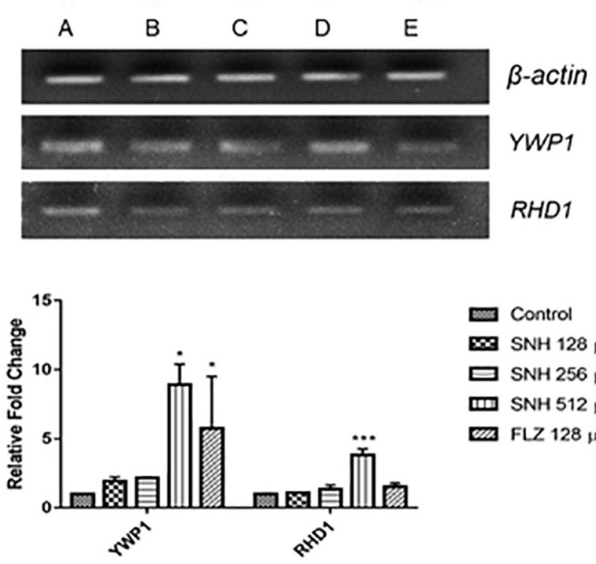
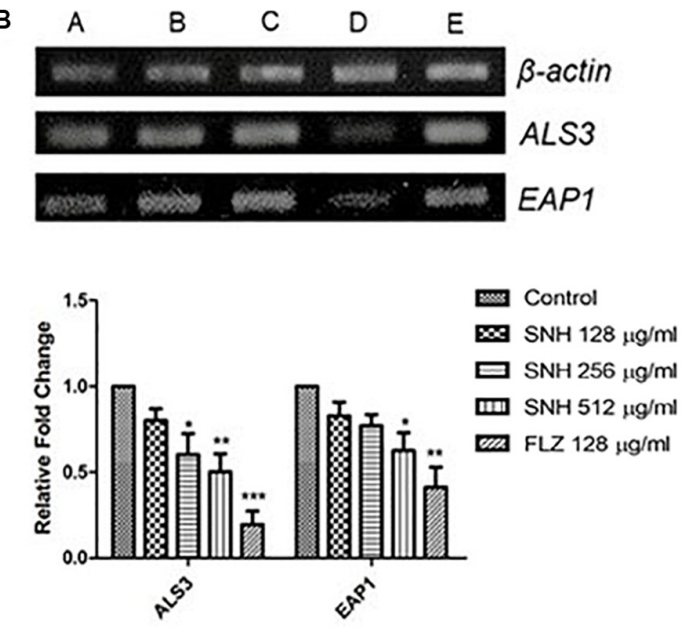

D
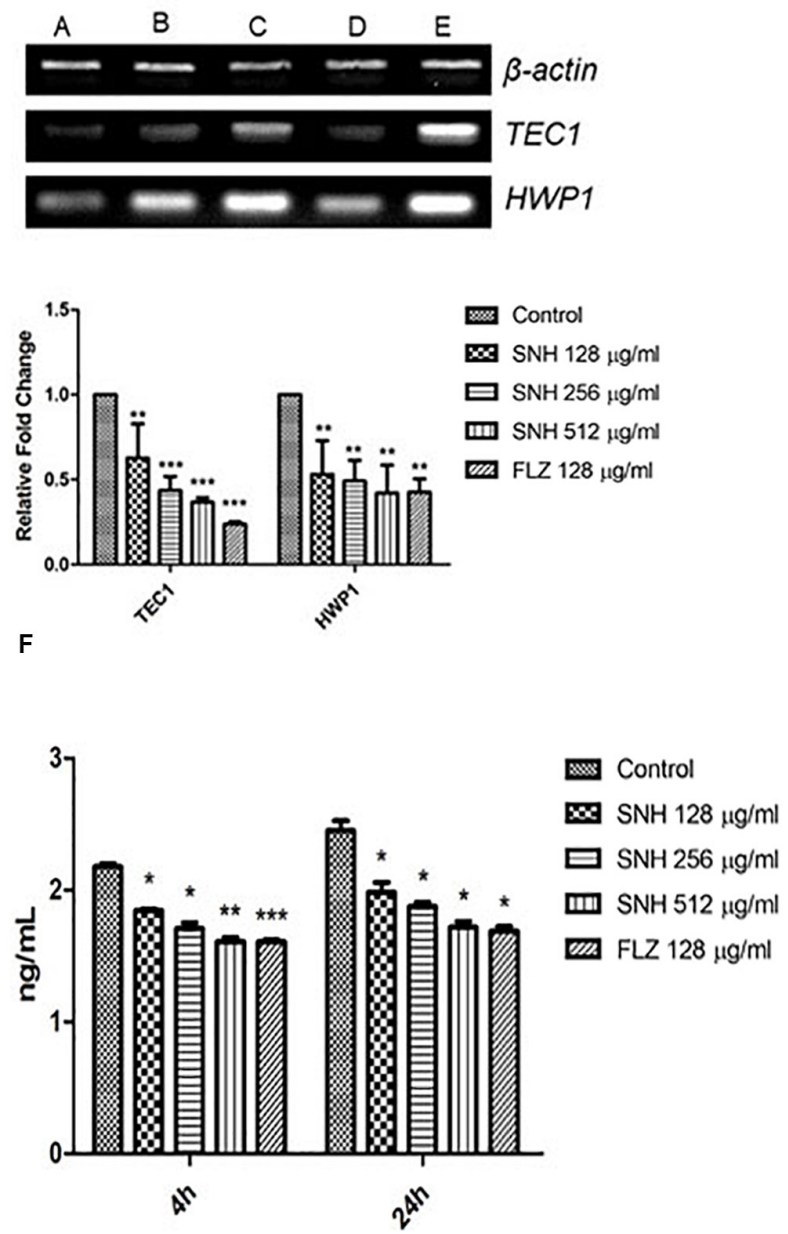

FIGURE 6 | Expression changes of biofilm related genes and protein of Ras1-cAMP-Efg1 pathway by SNH treatment in C. albicans SC5314. (A) The expression levels of adhesion-related genes ALA1 and ALS1. (B) The expression levels of biofilm-related genes ALS3 and EAP1. (C-D) The expression levels of

Ras1-CAMP-Efg1 pathway-related genes RAS1, EFG1, TEC1, and HWP1. (E) The expression of yeasts-related genes YWP1 and RHD1. Gene expression results were detected by RT-PCR nucleic acid electrophoresis bands and qRT-PCR quantitative analysis. The drug-free strain-containing medium was set as the control. Data are shown as mean $\pm \mathrm{SD}$. (A,B,C,D,E) were respectively expressed as SNH $512 \mu \mathrm{g} / \mathrm{mL}$ group, SNH $256 \mu \mathrm{g} / \mathrm{mL} \mathrm{group}, \mathrm{SNH} 128 \mu \mathrm{g} / \mathrm{mL}$ group, and FLZ $128 \mu \mathrm{g} / \mathrm{mL}$ group, Control group. ${ }^{*} p<0.05,{ }^{\star *} p<0.01$, and ${ }^{* \star *} p<0.001$ are calculated by comparing with the control group. (F) Effects of SNH on the production of cAMP protein of $C$. albicans SC5314. The drug-free strain-containing medium was set as the control. Data are shown as mean \pm SD. ${ }^{*} p<0.05,{ }^{* \star} p<0.01$, and ${ }^{\star \star *} p<0.001$ are calculated by comparing with the control group. 

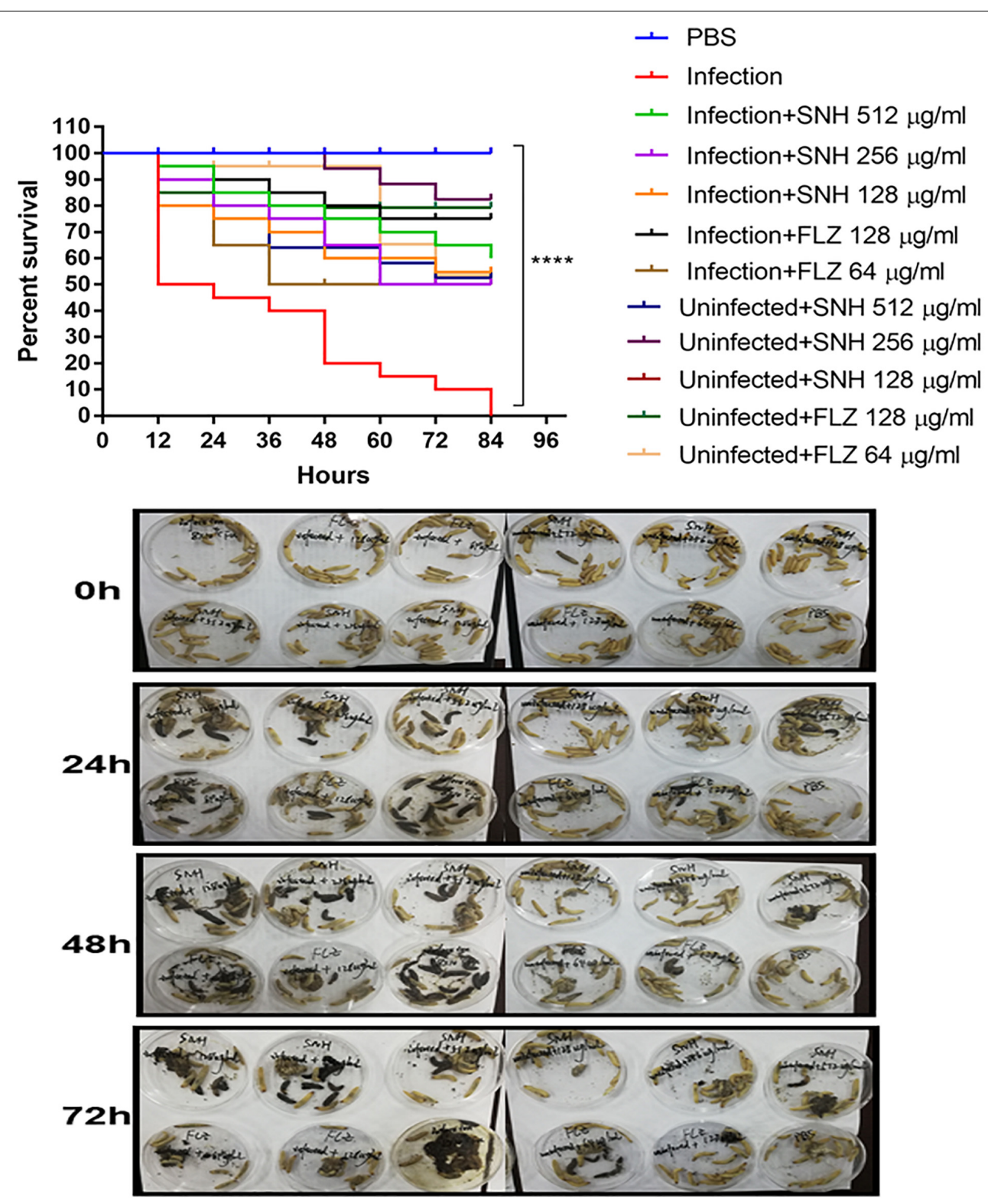

FIGURE 7 | In vivo evaluation of antifungal efficacy of SNH against C. albicans. Survival of G. mellonella larvae infected with LD50 dose of C. albicans SC5314 strains $\left(8 \times 10^{4} \mathrm{CFU} /\right.$ larvae) and treated with SNH $1 \mathrm{~h}$ post-infection. C. albicans SC5314 induced infection (10 $\left.\mu \mathrm{L}\right)$ was treated with SNH (10 $\left.\mu \mathrm{L}\right)$, keeping respective controls (infected, infected with FLZ-treatment, PBS). Data expressed as the mean of three independent experiments. Survival curves were plotted using the Kaplan-Meier method and statistical analysis were performed using the log-rank test for multiple comparisons. ${ }^{* \star \star *} p<0.0001$.

We speculated that the mechanism of SNH in C. albicans biofilm inhibition may be related to blocking the Ras1-cAMP-Efg1 signaling pathway.

\section{Determination of $\mathrm{LD}_{50}$ of $C$. albicans SC5314 Strains in G. mellonella Larvae}

Inoculation of $G$. mellonella with C. albicans SC5314 strains resulted larval killing in a fungal concentration-dependent manner (Supplementary Figure S3). Based on the survival study, $8 \times 10^{4} \mathrm{CFU} /$ larvae was determined as the $\mathrm{LD}_{50}$ in G. mellonella larvae.

\section{SNH Effectively Treats C. albicans Infection in vivo}

As shown in Figure 7, the survival rate in the PBS group was $100 \%$. The survival rate in the infected group was only $50 \%$ after $12 \mathrm{~h}$. In the next $72 \mathrm{~h}$, larvae in the infected group continued to die, and the final survival rate of the infected group was $0 \%$ after $84 \mathrm{~h}$. It can be seen that the $256 \mu \mathrm{g} / \mathrm{mL}$ and $128 \mu \mathrm{g} / \mathrm{mL}$ SNH control groups did not show obvious drug toxicity, and particularly in the uninfected $+\mathrm{SNH} 128 \mu \mathrm{g} / \mathrm{mL}$ group, no larvae died after $84 \mathrm{~h}$. The survival rate in the uninfected $+\mathrm{SNH}$ $256 \mu \mathrm{g} / \mathrm{mL}$ group was $85 \%$ after $84 \mathrm{~h}$, and the survival rate 


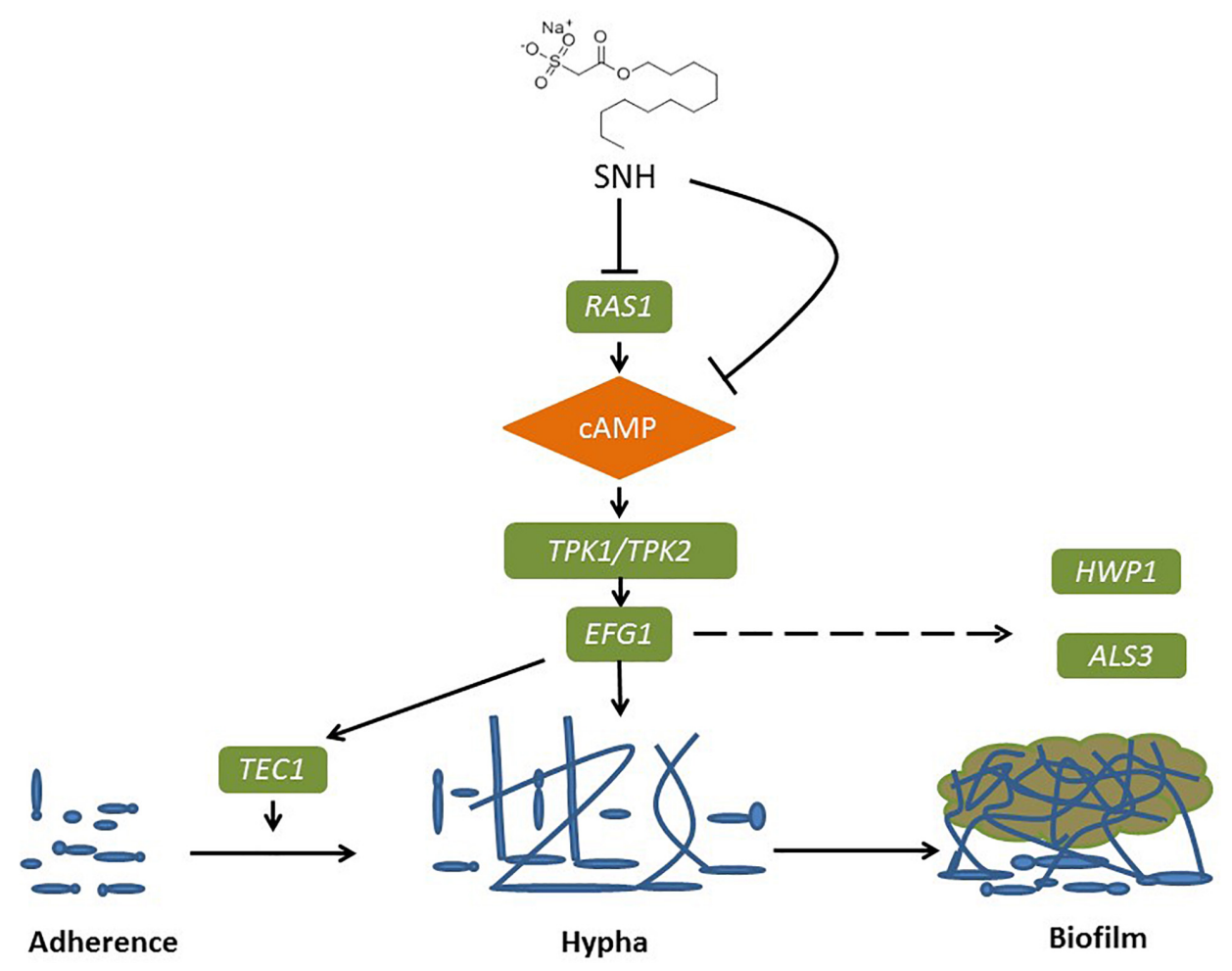

FIGURE 8 | Possible mechanism of SNH inhibits the biofilm formation of C. albicans by repression of Ras1-cAMP-Efg1 pathway.

of the uninfected $+\mathrm{SNH} 512 \mu \mathrm{g} / \mathrm{mL}$ group was $55 \%$ after $84 \mathrm{~h}$. These results indicate that $\mathrm{SNH}$ is slightly toxic at high concentrations, and $\mathrm{SNH}$ is not toxic at low concentrations. We further investigated the effects of $\mathrm{SNH}$ treatment at $1 \mathrm{~h}$ postinfection and found that the survival rate of the infection $+\mathrm{SNH}$ $512 \mu \mathrm{g} / \mathrm{mL}$ group was $60 \%$ after $60 \mathrm{~h}$, the survival rate of the infection + SNH $256 \mu \mathrm{g} / \mathrm{mL}$ group was $50 \%$ after $84 \mathrm{~h}$, and the survival rate of the infection + SNH $128 \mu \mathrm{g} / \mathrm{mL}$ group was $55 \%$ after $84 \mathrm{~h}$. These results show that compared with the survival rate of the infected group, the survival rate of all SNH dose groups remained at least above $50 \%$, and the difference was statistically significant $(p<0.0001)$. This indicates that SNH plays an obvious antifungal role in the body, thereby improving the survival rate of larvae infected by C. albicans.

\section{DISCUSSION}

The medical impact of Candida albicans is usually attributed to its ability to form biofilms, which are tightly packed cell communities that tightly adhere to a surface and are embedded in a protective polymer extracellular matrix (Simonetti et al., 2019). Fungal pathogens form biofilms that are highly resistant to antibacterial treatment. When yeast cells adhere to a solid surface in approximately $1-2 \mathrm{~h}$, the adherent cells proliferate and divide early, followed by biofilm formation, forming a complex three-dimensional structure, which is bound together by hyphae and an outer polymer matrix. After $24 \mathrm{~h}$ of cultivation, a mature biofilm is formed, which is a network of yeast, hyphae, pseudohyphae and extracellular material (Ramage et al., 2005; Lohse et al., 2018). In the current study, we demonstrated that $\mathrm{SNH}$ is effective in inhibiting the adhesion and biofilm formation of C. albicans. Importantly, SNH not only suppresses adhesion but also inhibits the formation of a mature biofilm. Adhesion is the first stage of biofilm development (Douglas, 2003). The adhesion of C. albicans was significantly decreased after $\mathrm{SNH}$ treatment, indicating that $\mathrm{SNH}$ inhibits biofilm formation by suppressing adhesion (Li et al., 2017). Furthermore, to prevent the formation of biofilms, the transformation of yeast cells to hyphae should be prevented (Kavanaugh et al., 2014), and we found that $\mathrm{SNH}$ can significantly repress the yeast-to-hypha morphological transition, which is key to the biofilm maturation of $C$. albicans. The present results suggest that the anti-biofilm activity of SNH may be attributed to its anti-adhesion and antimorphological transformation activities (Bachmann et al., 2002). Recently, Liu et al. (2020) revealed that sodium houttuyfonate, a derivative of $\mathrm{SNH}$, in combination with berberine, palmatine, jatrorrhizine, and cinnamaldehyde can synergistically inhibit several Candida isolates, and induce cell wall remodeling of these isolates. In XTT reduction assays, we found that $\mathrm{SNH}$ had strong antifungal activity within $4 \mathrm{~h}$ of initial adhesion, which was significantly better than $\mathrm{SNH}$ antifungal activity during the 24-h biofilm formation phase. Through inverted microscope observations, we found that $\mathrm{SNH}$ can effectively inhibit C. albicans adhesion during the initial adhesion phase, and $\mathrm{SNH}$ can inhibit large thick biofilm formation during the 
biofilm phase, but there were still many single fungal cells or small biofilms observable through CLSM and SEM. To further examine the effect of SNH on C. albicans biofilms in vitro, we also selected four clinical strains of C. albicans, and found that SNH can still effectively inhibit biofilm formation through quantification and crystal violet staining. We speculated whether these SNH anti-biofilm effects are related to fungicidal activity. A previous study found that the antimicrobial peptide VLL-28 can inhibit yeast cell growth in the suspended state, prevent cell adhesion and eliminate established biofilms in vitro, and also found that VLL-28 can reduce the quantity of Candida biofilms, but with no fungicidal effects (Roscetto et al., 2018). Our research also found that SNH inhibits the adhesion and growth of yeast cells and is effective against biofilms. SNH can reduce C. albicans biofilms, but cannot effectively kill fungi. This result can be interpreted by the ability of SNH to affect the structure and stability of the biofilm matrix by interacting with one or more components, thereby inducing the decomposition of the biofilm without killing the cells.

Oral infections caused by Candida are usually biofilms, and Candida is the most common fungal pathogens in humans (Millsop and Fazel, 2016; Vipulanandan et al., 2018). Biofilm resistance is an important factor in human disease. Candida biofilms represent an important virulence factor, and their reduction is particularly important in combating infection (Stringaro et al., 2018). Among the phenotypic changes observed in cells that form part of biofilms, the most clinically relevant feature is their increased resistance to antifungal therapy (Mukherjee and Chandra, 2004). Compared with plankton, biofilm cells can display an up to 1000 -fold increased resistance (Rossoni et al., 2019). Before conducting clinical trials, in vivo studies should be conducted to assess the potential antifungal effect of SNH in C. albicans. In determining the potential toxicity of fungal pathogens, mature Galleria mellonella larvae have proven to be a promising substitute for mammals (Glavis-Bloom et al., 2012; Arvanitis et al., 2013). The current study is the first to investigate the anti-C. albicans properties of SNH using G. mellonella. The results show that SNH has a therapeutic effect on C. albicans infection in vivo, and this is maintained after $24 \mathrm{~h}$ of mature biofilm formation. In the following $60 \mathrm{~h}$, compared with the infection group where larvae continued to die until the survival rate was $0 \%$, the $\mathrm{SNH}$ groups maintained a survival rate of more than $50 \%$. The present study shows that SNH has an antifungal biofilm effect both in vitro and in vivo.

Because of the increased abuse of traditional antifungal drugs and antibiotics, the resistance of C. albicans, especially to FLZ, is increasing. Antifungal treatment faces serious hurdles, and there is an urgent need to find new antifungal drugs. To date, most of the reported chemicals that claim to have potential antifungal functions have a high MIC. However, these antifungal agents usually have a strong resistance reversal potential in FLZresistant C. albicans (Letscher-Bru et al., 2013; Padmavathi et al., 2015). Therefore, it may be necessary to find a new drug that can increase the antifungal activity of FLZ as another method to expand the antifungal library (Guo et al., 2008). Studies have found that $\mathrm{SH}$ and FLZ have a synergistic effect in FLZresistant $C$. albicans, and $\mathrm{SH}$ has strong potential to enhance
FLZ treatment (Shao et al., 2017). Since higher MIC values may hinder the future development of pharmaceutical products, the combination of different forms of Chinese medicine monomers and traditional antifungal drugs is conducive to realizing the effectiveness of anti-fungal pathogens. Liu et al. reported a good antifungal effect through the combination of $\mathrm{SH}$ and various traditional Chinese medicine monomers (Liu et al., 2020). Here, we chose SNH and four antifungals and observed changes in the MIC and biofilm formation, and found that SNH combined with four antifungals has a significant antifungal biofilm effect. It is suggested that $\mathrm{SH}$ or $\mathrm{SNH}$ could have significant clinical potential in combination with different antifungals, in terms of reducing MIC, and producing significant anti-biofilm effects, providing treatment options for the clinical treatment of fungal infections.

With the development of genomics and the advent of whole genome sequencing platforms, metabolic pathways and related genes involved in fungal pathogenesis have been revealed (Chong et al., 2018). The current study found that the anti-adhesive effects of SNH are more significant than its anti-biofilm effects, and to verify that $\mathrm{SNH}$ may inhibit biofilm formation by inhibiting initial adhesion, we sequenced the transcriptome of C. albicans at an initial adhesion phase in $256 \mu \mathrm{g} / \mathrm{mL}\left(1 \mathrm{MIC}_{80}\right)$ SNH treatment and control groups through a high-throughput RNA sequencing method. Compared with the genomic data, the transcriptomic analysis provided more significant information about the relevant genes under different conditions (Grumaz et al., 2013; Giosa et al., 2017). To clarify the anti-adhesion and anti-biofilm mechanism of SNH, further PCR results were combined with GO enrichment analysis of the transcriptome sequencing results. Compared with the control group, the expression of 611 genes, including 361 down-regulated and 250 up-regulated genes, was significantly altered in the SNH group. Among these, several important adhesion- and biofilm-related genes were down-regulated after SNH treatment such as RAS1, $A L S 3$, and HWP1, which are components of the Ras1-cAMP-Efg1 pathway. The down-regulation of these genes may contribute to the anti-adhesive and anti-biofilm activity of SNH. We found that the expression of ALS1, ALA1, ALS3, EAP1, RAS1, EFG1, $H W P 1$, and TEC1 in the Ras1-cAMP-Efg1 pathway of C. albicans was significantly down-regulated after SNH treatment in a dosedependent manner and the expression of YWP1 and RHD1 of C. albicans was up-regulated after SNH treatment in a dosedependent manner, as assessed through qRT-PCR and semi-qRTPCR assays.

The Ras1-cAMP-Efg1 pathway is responsible for the adhesion, yeast-hyphal transition, biofilm formation and virulence of C. albicans (Davis-Hanna et al., 2008). Compounds of natural origin may represent a new strategy to prevent fungal adhesion and biofilm formation (De Vita et al., 2014). Certain natural products, such as magnolol and honokiol, can inhibit the adhesion, yeast-hyphal transition and biofilm formation of C. albicans through inactivation of the Ras1-cAMP-Efg1 pathway (Sun et al., 2015). More specifically, Ras plays a key role in controlling yeast/hyphal morphogenesis, cell adhesion and biofilm formation in C. albicans (Piispanen et al., 2011). Accordingly, EFG1 is the central regulator of biofilm formation of C. albicans (Theberge et al., 2013). It is essential for Candidulin 
growth, and is considered to be essential for the interaction between C. albicans and human host cells (Stoldt et al., 1997). The TEC1 gene, encoding transcription factors, positively regulates the expression of hypha-specific genes such as HWP1 and ALS3 (Panariello et al., 2017). The ALS gene family plays an essential role in the adherence stage of $C$. albicans, and contributes to the invasion of cells and subsequently host cell damage (Sundstrom, 2002; Liu and Filler, 2011). ALA1 and $A L S 1$ encode proteins that increase adherence, and produce germ tubes that exhibit thigmotropic behavior and seek solid surfaces, and grow within host tissues (Hoyer et al., 1995; Sundstrom, 2002). HWP1 codes for a cell surface glycoprotein targeted by mammalian transglutaminase that is required for cell adhesive interactions during biofilm formation (Ene and Bennett, 2009). The involvement of HWP1 in C. albicans adhesion is supported by the EAP1 gene which encodes a glucan-crosslinked cell wall protein (Li and Palecek, 2003). Similar to many other genes, HWP1 and EAP1 are downstream effectors of EFG1 and NRG1 as transcription factors ( $\mathrm{Li}$ and Palecek, 2003; Remmele et al., 2015). Furthermore, expressed cell wall adhesions, including ALS and $H W P$, are crucial for $C$. albicans attachment to host tissue and for multispecies biofilm formation (Theberge et al., 2013). Notably, ALS1, ALS3, and HWP1 play complementary roles during biofilm formation suggesting that they might interact to promote adhesion between adjacent cellular surfaces (Lo et al., 1997). Both ALS3 and HWP1 are developmentally regulated and exclusively expressed in C. albicans hyphae (Hoyer et al., 1998), which falls under the domain of the cAMP-protein kinase-A signaling pathway that regulates yeast-hypha morphogenesis via the transcription factor EFG1 (Lo et al., 1997; Hoyer et al., 1998; Bastidas et al., 2009; Zhang et al., 2017). Overall, HWP1 is a downstream component of the cAMP-dependent PKA pathway and is positively regulated by EFG1 (Lin et al., 2018). The results of PCR and eukaryotic transcriptome sequencing show that $\mathrm{SNH}$ can inhibit the gene expression of $A L S 1, A L A 1$, ALS3, EAP1, RAS1, EFG1, HWP1, and TEC1 in the Ras1cAMP-Efg1 pathway of C. albicans. In addition, we determined the effects of $\mathrm{SNH}$ on the production of cAMP which is the key messenger molecule in the Ras1-cAMP-Efg1 pathway of C. albicans. Previous studies have found that the yeast-tomycelium transition of $C$. albicans is positively regulated by the Ras1-cAMP-Efg1 and MAPK signaling pathways, while cAMP is an intermediate regulator of morphogenesis (Chang et al., 2012). The results showed that SNH can also effectively repress the production of cAMP at two different time points (4 and $24 \mathrm{~h}$ ) throughout the C. albicans growth cycle. Combined with the transcriptome and $\mathrm{qRT}-\mathrm{PCR}$ results, these data suggest that $\mathrm{SNH}$ inhibits the activity of the Ras-cAMP-Efg1 pathway and leads to an alteration to mechanisms underlying $C$. albicans adherence growth, yeast-hyphal transition and biofilm formation (Figure 8). In addition, a previous study found that YWP1deficient blastoconidia exhibited increased adhesiveness and biofilm formation, suggesting that YWP1 may promote the dispersal of yeast forms of C. albicans (Granger et al., 2005). We also evaluated the expression of the yeast-specific gene RHD1, and previous studies have shown that expression patterns of Candida species-related genes are significantly increased during hyphae-specific gene expression over the duration of biofilm formation. On the contrary, the expression of genes suppressing yeast-specific genes (RHD1) and filament formation was decreased (Park et al., 2014; Lee et al., 2017). Since YWP1 and $R H D 1$ play a negative regulatory role in the adhesion of yeast-like cells, the adhesion of biofilms formed by YWP1- or RHD1-deficient strains is enhanced (Chandra et al., 2001; Znaidi et al., 2013). Therefore, we detected through PCR that the relative expression levels of YWP1 and RHD1 genes in the SNH treatment group were increased in the 24-h biofilm state compared with the control group.

It has been reported that FLZ can exert antifungal effects by regulating the Ras-cAMP-PKA signaling pathway (Liu et al., 2017; Sun et al., 2019). Coincidentally, our experimental results also found that FLZ can down-regulate the expression of genes related to the Ras1-cAMP-Efg1 signaling pathway and the secretion level of cAMP, which demonstrates that FLZ could exert antifungal effects by regulating the Ras1-cAMPEfg1 signaling pathway. At present, there are no reports that SNH can exert antifungal effects through the Ras1-cAMP-Efg1 signaling pathway. However, we were surprised to find that $\mathrm{SNH}$ can down-regulate the expression of genes related to the Ras1cAMP-Efg1 signaling pathway and the secretion level of CAMP. The mechanism of SNH against C. albicans may be related to the regulation of the Ras1-cAMP-Efg1 signaling pathway. In the future, studies are required to investigate the hyphae invasion/virulence of SNH-treated C. albicans, with relevant cell experiments to investigate possible mechanisms. In addition, by optimizing the chemical structure of $\mathrm{SNH}$, its bioavailability was improved. Slow release drug delivery agents could also be used to prolong the release and action time of $\mathrm{SNH}$.

\section{CONCLUSION}

In summary, through in vivo and in vitro experiments, it was found that $\mathrm{SNH}$ has an obvious anti-C. albicans biofilm and infection effect. In addition, SNH combined with other antifungals can have synergistic efficacy in terms of anti-C. albicans biofilm effects. The results of eukaryotic transcriptome sequencing and PCR indicated that the antiC. albicans biofilm mechanism of SNH may be closely related to the Ras1-cAMP-Efg1 pathway. Further gene knockout studies are required to verify that $\mathrm{SNH}$ regulates this pathway to inhibit adhesion, yeast hypha transition and biofilm formation. Our results reveal potential new applications for existing natural products of Houttuynia cordata which is an edible vegetable and traditional Chinese herb that has potential as a treatment to inhibit opportunistic fungal pathogens.

\section{DATA AVAILABILITY STATEMENT}

The datasets presented in this study can be found in online repositories. The names of the repository/repositories and accession number(s) can be found below: https://www.ncbi.nlm. nih.gov/sra/PRJNA544616, PRJNA544616. 


\section{AUTHOR CONTRIBUTIONS}

DW, GY, and CW conceived and designed the study. JW and DW wrote the manuscript. JS and TW critically reviewed the manuscript and provided general advice. JW, YS, YZ, and LM performed the experiments and analyzed the data. All authors have read and agreed to the published version of the manuscript.

\section{FUNDING}

The research was funded by the National Natural Science Foundation of China (Grant No. 81503115), China Postdoctoral Science Foundation (Grant No. 2019M662185), Outstanding Young Talents Key Project of Anhui Institution of Higher Education, Provincial first-class undergraduate program (Grant No. 2018ylzy057), and Natural Science Foundation of Anhui Province (Grant No. 2008085MH300). The Funding is used to cover laboratory expenses, sample preparation, and sequencing. These funding agencies have no role in research design, data collection, analysis of results, or manuscript writing.

\section{REFERENCES}

Albrecht, A., Felk, A., Pichova, I., Naglik, J. R., Schaller, M., de Groot, P., et al. (2006). Glycosylphosphatidylinositol-anchored proteases of Candida albicans target proteins necessary for both cellular processes and host-pathogen interactions. J. Biol. Chem. 281, 688-694. doi: 10.1074/jbc.M509297200

Arvanitis, M., Glavis-Bloom, J., and Mylonakis, E. (2013). Invertebrate models of fungal infection. Biochim. Biophys. Acta 1832, 1378-1383. doi: 10.1016/j.bbadis. 2013.03.008

Bachmann, S. P., Vandewalle, K., Ramage, G., Patterson, T. F., Wickes, B. L., Graybill, J. R., et al. (2002). In vitro activity of caspofungin against Candida albicans biofilms. Antimicrob. Agents 46, 3591-3596. doi: 10.1128/aac.46.11. 3591-3596.2002

Barchiesi, F., Colombo, A. L., McGough, D. A., and Rinaldi, M. G. (1994). Comparative study of broth macrodilution and microdilution techniques for in vitro antifungal susceptibility testing of yeasts by using the National Committee for Clinical Laboratory Standards' proposed standard. J. Clin. Microbiol. 32, 2494-2500. doi: 10.1128/jcm.32.10.2494-2500.1994

Bastidas, R. J., Heitman, J., and Cardenas, M. E. (2009). The protein kinase Tor1 regulates adhesin gene expression in Candida albicans. PLoS Pathog. 5:e1000294. doi: 10.1371/journal.ppat.1000294

Bergin, D., Murphy, L., Keenan, J., Clynes, M., and Kavanagh, K. (2006). Preexposure to yeast protects larvae of Galleria mellonella from a subsequent lethal infection by Candida albicans and is mediated by the increased expression of antimicrobial peptides. Microbes Infect. 8, 2105-2112. doi: 10.1016/j.micinf. 2006.03.005

Boufridi, A., and Quinn, R. J. (2018). Harnessing the properties of natural products. Annu. Rev. Pharmacol. 58, 451-470. doi: 10.1146/annurev-pharmtox-010716105029

Chandra, J., Mukherjee, P. K., Leidich, S. D., Faddoul, F. F., Hoyer, L. L., Douglas, L. J., et al. (2001). Antifungal resistance of Candidal biofilms formed on denture acrylic in vitro. J. Dent. Res. 80, 903-908. doi: 10.1177/00220345010800031101

Chang, W., Li, Y., Zhang, L., Cheng, A., and Lou, H. (2012). Retigeric acid B attenuates the virulence of Candida albicans via inhibiting adenylyl cyclase activity targeted by enhanced farnesol production. PLoS One 7:e41624. doi: 10.1371/journal.pone.0041624

Chong, P. P., Chin, V. K., Wong, W. F., Madhavan, P., Yong, V. C., and Looi, C. Y. (2018). Transcriptomic and genomic approaches for unravelling Candida

\section{ACKNOWLEDGMENTS}

We thank the sequencing facilities of Majorbio Gene Cloud Platform for the preparation, sequencing, and bioinformatics analysis of the transcriptome data.

\section{SUPPLEMENTARY MATERIAL}

The Supplementary Material for this article can be found online at: https://www.frontiersin.org/articles/10.3389/fmicb. 2020.02075/full\#supplementary-material

FIGURE S1 | Volcano plot diagram of the extent of the gene differential expression between two groups.

FIGURE S2 | Hierarchical cluster analysis of the 611 significantly expression changing genes between two groups.

FIGURE S3 | Determination of $\mathrm{LD}_{50}$ of C. albicans SC5314 strains in G. mellonella larvae.

TABLE S1 | Expression changes of several genes in Ras1-cAMP-Efg1 pathway determined by transcriptomic analysis.

TABLE S2 | Complete list of genes with significantly expression changes determined by transcriptomic analysis.

albicans biofilm formation and drug resistance-an update. Genes 9:540. doi: 10.3390/genes 9110540

Davis-Hanna, A., Piispanen, A. E., Stateva, L. I., and Hogan, D. A. (2008). Farnesol and dodecanol effects on the Candida albicans Ras1-cAMP signaling pathway and the regulation of morphogenesis. Mol. Microbiol. 67, 47-62. doi: 10.1111/j. 1365-2958.2007.06013.x

De Vita, D., Friggeri, L., D’Auria, F. D., Pandolfi, F., Piccoli, F., Panella, S., et al. (2014). Activity of caffeic acid derivatives against Candida albicans biofilm. Bioorg. Med. Chem. Lett. 24, 1502-1505. doi: 10.1016/j.bmcl.2014.02.005

Douglas, L. J. (2003). Candida biofilms and their role in infection. Trends Microbiol. 11, 30-36. doi: 10.1016/s0966-842x(02)00002-1

Ene, I. V., and Bennett, R. J. (2009). Hwpl and related adhesins contribute to both mating and biofilm formation in Candida albicans. Eukaryot. Cell. 8, 1909-1913. doi: 10.1128/EC.00245-09

Giosa, D., Felice, M. R., Lawrence, T. J., Gulati, M., Scordino, F., Giuffrè, L., et al. (2017). Whole RNA-sequencing and transcriptome assembly of Candida albicans and Candida africana under chlamydospore-inducing conditions. Genome Biol. Evol. 9, 1971-1977. doi: 10.1093/gbe/evx143

Glavis-Bloom, J., Muhammed, M., and Mylonakis, E. (2012). Of model hosts and man: using Caenorhabditis elegans, Drosophila melanogaster and Galleria mellonella as model hosts for infectious disease research. Adv. Exp. Med. Biol. 710, 11-17. doi: 10.1007/978-1-4419-5638-5_2

Granger, B. L., Flenniken, M. L., Davis, D. A., Mitchell, A. P., and Cutler, J. E. (2005). Yeast wall protein 1 of Candida albicans. Microbiology 151, 1631-1644. doi: 10.1099/mic.0.27663-0

Grumaz, C., Lorenz, S., Stevens, P., Lindemann, E., Schöck, U., Retey, J., et al. (2013). Species and condition specific adaptation of the transcriptional landscapes in Candida albicans and Candida dubliniensis. BMC Genomics 14:212. doi: 10.1186/1471-2164-14-212

Guo, X. L., Leng, P., Yang, Y., Yu, L. G., and Lou, H. X. (2008). Plagiochin E, a botanicderived phenolic compound, reverses fungal resistance to fluconazole relating to the efflux pump. J. Appl. Microbiol. 104, 831-838. doi: 10.1111/j. 1365-2672.2007.03617.x

Harding, C. R., Schroeder, G. N., Collins, J. W., and Frankel, G. (2013). Use of Galleria mellonella as a model organism to study Legionella pneumophila infection. J. Vis. Exp. 81:e50964. doi: 10.3791/50964

Holm, K., Svensson, P. J., and Rasmussen, M. (2015). Invasive Fusobacterium necrophorum infections and Lemièrre's syndrome: the role of thrombophilia 
and EBV. Eur. J. Clin. Microbiol. 34, 2199-2207. doi: 10.1007/s10096-0152469-8

Hoyer, L. L., Payne, T. L., Bell, M., Myers, A. M., and Scherer, S. (1998). Candida albicans ALS3 and insights into the nature of the ALS gene family. Curr. Genet. 33, 451-459. doi: 10.1007/s002940050359

Hoyer, L. L., Scherer, S., Shatzman, A. R., and Livi, G. P. (1995). Candida albicans ALS1: Domains related to a Saccharomyces cerevisiae sexual agglutinin separated by a repeating motif. Mol. Microbiol. 15, 39-54. doi: 10.1111/j.13652958.1995.tb02219.x

Huang, W., Duan, Q., Li, F., Shao, J., Cheng, H., and Wu, D. (2015). Sodium houttuyfonate and EDTA-Na2 in combination effectively inhibits Pseudomonas aeruginosa, Staphylococcus aureus and Candida albicans in vitro and in vivo. Bioorg. Med. Chem. Lett. 25, 142-147. doi: 10.1016/j.bmcl.2014.10.072

Jiang, C., Yu, J., Qin, S., Zhao, J., and Yu, Z. (2006). Acute toxicity study of sodium new houttuyfonate. J. Anim. Sci. Vet. Med. 38, 54-55.

Jiang, R., Hu, C., Li, Q., Cheng, Z., Gu, L., Li, H., et al. (2019). Sodium new houttuyfonate suppresses metastasis in NSCLC cells through the Linc00668/miR-147a/slug axis. J. Exp. Clin. Cancer Res. 38:155. doi: 10.1186/ s13046-019-1152-9

Kavanaugh, N. L., Zhang, A. Q., Nobile, C. J., Johnson, A. D., and Ribbeck, K. (2014). Mucins suppress virulence traits of Candida albicans. mBio 5:e01911. doi: 10.1128/mBio.01911-14

Lee, K. H., Park, S. J., Choi, S. J., and Park, J. Y. (2017). Proteus vulgaris and Proteus mirabilis decrease Candida albicans biofilm formation by suppressing morphological transition to its hyphal form. Yonsei Med. J. 58, 1135-1143. doi: 10.3349/ymj.2017.58.6.1135

Letscher-Bru, V., Obszynski, C., Samsoen, M., Sabou, M., Waller, J., and Candolfi, E. (2013). Antifungal activity of sodium bicarbonate against fungal agents causing superficial infections. Mycopathologia 175, 153-158. doi: 10.1007/ s11046-012-9583-2

Li, B., and Dewey, C. N. (2011). RSEM: accurate transcript quantification from RNA-Seq data with or without a reference genome. BMC Bioinformatics 12:323. doi: 10.1186/1471-2105-12-323

Li, D. D., Chai, D., Huang, X. W., Guan, S. X., Du, J., Zhang, H. Y., et al. (2017). Potent in vitro synergism of fFluconazole and osthole against fluconazoleresistant Candida albicans. Antimicrob. Agents Chemother. 61:e436-e417. doi: 10.1128/AAC.00436-17

Li, F., and Palecek, S. P. (2003). EAP1, a Candida albicans gene involved in binding human epithelial cells. Eukaryot Cell. 2, 1266-1273. doi: 10.1128/ec.2.6.12661273.2003

Lin, C. J., Wu, C. Y., Yu, S. J., and Chen, Y. L. (2018). Protein kinase A governs growth and virulence in Candida tropicalis. Virulence 9, 331-347. doi: 10.1080/ 21505594.2017.1414132

Liu, J., Li, Q., Wang, C., Shao, J., Wang, T., Wu, D., et al. (2020). Antifungal evaluation of traditional herbal monomers and their potential for inducing cell wall remodeling in Candida albicans and Candida auris. Biofouling 36, 319-331. doi: 10.1080/08927014.2020.1759559

Liu, X., Li, T., Wang, D., Yang, Y., Sun, W., Liu, J., et al. (2017). Synergistic antifungal effect of fluconazole combined with licofelone against resistant Candida albicans. Front. Microbiol. 8:2101. doi: 10.3389/fmicb.2017.02101

Liu, Y., and Filler, S. G. (2011). Candida albicans Als3, a multifunctional adhesin and invasin. Eukaryot. Cell. 10, 168-173. doi: 10.1128/EC.00279-10

Livak, K. J., and Schmittgen, T. D. (2001). Analysis of relative gene expression data using real-time quantitative PCR and the 2(-Delta Delta C (T)) Method. Methods 25, 402-408. doi: 10.1006/meth.2001.1262

Lo, H. J., Köhler, J. R., Didomenico, B., Loebenberg, D., Cacciapuoti, A., and Fink, G. R. (1997). Nonfilamentous C. albicans mutants are avirulent. Cell 90, 939-949. doi: 10.1016/s0092-8674(00)80358-x

Lohse, M. B., Gulati, M., Johnson, A. D., and Nobile, C. J. (2018). Development and regulation of single- and multi-species Candida albicans biofilms. Nat. Rev. Microbiol. 16, 19-31. doi: 10.1038/nrmicro.2017.107

Lou, X., Luan, Y., Jiang, B., Chen, X., and Zhong, D. (2012). Acute toxicity of sodium houttuyfonate in BALB/c mice and its injury to cells. Chin. J. Pharmacol. Toxicol. 26, 653-657. doi: 10.3867/j.issn.1000-3002.2012.05.010

Lu, X., Yang, X., Li, X., Lu, Y., Ren, Z., Zhao, L., et al. (2013). In vitro activity of sodium new houttuyfonate alone and in combination with oxacillin or netilmicin against methicillin-resistant Staphylococcus aureus. PLoS One 8:e68053. doi: 10.1371/journal.pone.0068053
Manoharan, R. K., Lee, J. H., Kim, Y. G., Kim, S. I., and Lee, J. (2017a). Inhibitory effects of the essential oils $\alpha$-longipinene and linalool on biofilm formation and hyphal growth of Candida albicans. Biofouling 33, 143-155. doi: 10.1080/ 08927014.2017.1280731

Manoharan, R. K., Lee, J. H., Kim, Y. G., and Lee, J. (2017b). Alizarin and chrysazin inhibit biofilm and hyphal formation by Candida albicans. Front. Cell. Infect. Microbiol. 7:447. doi: 10.3389/fcimb.2017.00447

Manoharan, R. K., Lee, J. H., and Lee, J. (2017c). Antibiofilm and antihyphal activities of cedar leaf essential oil, camphor, and fenchone derivatives against Candida albicans. Front. Microbiol. 8:1476. doi: 10.3389/fmicb.2017.01476

Martin, H., Govern, M. M., Abbey, L., Gilroy, A., Mullins, S., Howell, S., et al. (2018). Inhibition of adherence of the yeast Candida albicans to buccal epithelial cells by synthetic aromatic glycoconjugates. Eur. J. Med. Chem. 160, 82-93. doi: 10.1016/j.ejmech.2018.10.011

Millsop, J. W., and Fazel, N. (2016). Oral candidiasis. Clin. Dermatol. 34, 487-494. doi: 10.1016/j.clindermatol.2016.02.022

Mukherjee, P. K., and Chandra, J. (2004). Candida biofilm resistance. Drug. Resist. Updat. 7, 301-309. doi: 10.1016/j.drup.2004.09.002

Naglik, J. R., Fostira, F., Ruprai, J., Staab, J. F., Challacombe, S. J., and Sundstrom, P. (2006). Candida albicans HWP1 gene expression and host antibody responses in colonization and disease. J. Med. Microbiol. 55, 1323-1327. doi: 10.1099/jmm. 0.46737-0

Oshiro, K. G. N., Rodrigues, G., Monges, B. E. D., Cardoso, M. H., and Franco, O. L. (2019). Bioactive peptides against fungal biofilms. Front. Microbiol. 10:2169. doi: $10.3389 /$ fmicb.2019.02169

Padmavathi, A. R., Bakkiyaraj, D., Thajuddin, N., and Pandian, S. K. (2015). Effect of 2, 4-di-tert-butylphenol on growth and biofilm formation by an opportunistic fungus Candida albicans. Biofouling 31, 565-574. doi: 10.1080/ 08927014.2015.1077383

Panariello, B. H. D., Klein, M. I., Pavarina, A. C., and Duarte, S. (2017). Inactivation of genes TEC1 and EFG1 in Candida albicans influences extracellular matrix composition and biofilm morphology. J. Oral Microbiol. 9:1385372. doi: 10. 1080/20002297.2017.1385372

Park, S. J., Han, K. H., Park, J. Y., Choi, S. J., and Lee, K. H. (2014). Influence of bacterial presence on biofilm formation of Candida albicans. Yonsei Med. J. 55, 449-458. doi: 10.3349/ymj.2014.55.2.449

Pfaller, M. A., and Barry, A. L. (1994). Evaluation of a novel colorimetric broth microdilution method for antifungal susceptibility testing of yeast isolates. J. Clin. Microbiol. 32, 1992-1996. doi: 10.1128/jcm.32.8.1992-1996.1994

Piispanen, A. E., Bonnefoi, O., Carden, S., Deveau, A., Bassilana, M., and Hogan, D. A. (2011). Roles of Ras1 membrane localization during Candida albicans hyphal growth and farnesol response. Eukaryot. Cell. 10, 1473-1484. doi: 10. 1128/EC.05153-11

Pizarrocerda, J., and Cossart, P. (2006). Bacterial adhesion and entry into host cells. Cell 124, 715-727. doi: 10.1016/j.cell.2006.02.012

Ramage, G., Saville, S. P., Thomas, D. P., and López-Ribot, J. L. (2005). Candida biofilms: an update. Eukaryot Cell. 4, 633-638. doi: 10.1128/EC.4.4.633-638. 2005

Remmele, C. W., Luther, C. H., Balkenhol, J., Dandekar, T., Müller, T., and Dittrich, M. T. (2015). Integrated inference and evaluation of host-fungi interaction networks. Front. Microbiol. 6:764. doi: 10.3389/fmicb.2015.00764

Robinson, M. D., McCarthy, D. J., and Smyth, G. K. (2010). EdgeR: a Bioconductor package for differential expression analysis of digital gene expression data. Bioinformatics 26, 139-140. doi: 10.1093/bioinformatics/btp616

Rodriguezcerdeira, C., Gregorio, M. C., Molares-Vila, A., López-Barcenas, A., Fabbrocini, G., Bardhi, B., et al. (2019). Biofilms and vulvovaginal candidiasis. Colloids Surf. B Biointerfaces 174, 110-125. doi: 10.1016/j.colsurfb.2018.11.011

Roscetto, E., Contursi, P., Vollaro, A., Fusco, S., Notomista, E., and Catania, M. R. (2018). Antifungal and anti-biofilm activity of the first cryptic antimicrobial peptide from an archaeal protein against Candida spp. clinical isolates. Sci. Rep. 8:17570. doi: 10.1038/s41598-018-35530-0

Rossoni, R. D., de Barros, P. P., Lopes, L., Ribeiro, F. C., Nakatsuka, T., Kasaba, H., et al. (2019). Effects of surface pre-reacted glass-ionomer (S-PRG) eluate on Candida spp.: antifungal activity, anti-biofilm properties, and protective effects on Galleria mellonella against C. albicans infection. Biofouling 35, 997-1006. doi: 10.1080/08927014.2019.1686485

Shao, J., Cui, Y., Zhang, M., Wang, T., Wu, D., and Wang, C. (2017). Synergistic in vitro activity of sodium houttuyfonate with fluconazole against clinical 
Candida albicans strains under planktonic growing conditions. Pharm. Biol. 55, 355-359. doi: 10.1080/13880209.2016.1237977

Shen, S., Park, J. W., Huang, J., Dittmar, K. A., Lu, Z. X., Zhou, Q., et al. (2012). MATS: a Bayesian framework for flexible detection of differential alternative splicing from RNA-Seq data. Nucleic Acids Res. 40:e61. doi: 10.1093/nar/ gkr1291

Silva, D. R., Rosalen, P. L., Freires, I. A., Sardi, J., Lima, R. F., Lazarini, J. G., et al. (2019). Anadenanthera Colubrina vell Brenan: anti-Candida and antibiofilm activities, toxicity and therapeutical action. Braz. Oral Res. 33:e023. doi: 10. 1590/1807-3107bor-2019.vol33.0023

Simon, G., Berube, C., Voyer, N., and Grenier, D. (2018). Anti-biofilm and antiadherence properties of novel cyclic dipeptides against oral pathogens. Bioorg. Med. Chem. 27, 2323-2331. doi: 10.1016/j.bmc.2018.11.042

Simonetti, G., Palocci, C., Valletta, A., Kolesova, O., Chronopoulou, L., Donati, L., et al. (2019). Anti-Candida biofilm activity of pterostilbene or crude extract from non-fermented grape pomace entrapped in biopolymeric nanoparticles. Molecules 24:2070. doi: 10.3390/molecules24112070

Stoldt, V. R., Sonneborn, A., Leuker, C. E., and Ernst, J. F. (1997). Efglp, an essential regulator of morphogenesis of the human pathogen Candida albicans, is a member of a conserved class of bHLH proteins regulating morphogenetic processes in fungi. EMBO J. 16, 1982-1991. doi: 10.1093/emboj/16. 8.1982

Stringaro, A., Colone, M., and Angiolella, L. (2018). Antioxidant, antifungal, antibiofilm, and cytotoxic activities of mentha spp. essential oils. Medicines 5:112. doi: 10.3390/medicines5040112

Sun, L., Liao, K., and Wang, D. (2015). Effects of magnolol and honokiol on adhesion, yeast-hyphal transition, and formation of biofilm by Candida albicans. PLoS One 10:e0117695. doi: 10.1371/journal.pone.0117695

Sun, W., Zhang, L., Lu, X., Feng, L., and Sun, S. (2019). The synergistic antifungal effects of sodium phenylbutyrate combined with azoles against Candida albicans via the regulation of the Ras-cAMP-PKA signalling pathway and virulence. Can. J. Microbiol. 65, 105-115. doi: 10.1139/cjm-2018-0337

Sundstrom, P. (2002). Adhesion in Candida spp. Cell. Microbiol. 4, 461-469. doi: 10.1046/j.1462-5822.2002.00206.x

Tan, Y., Leonhard, M., Moser, D., Ma, S., and Schneider-Stickler, B. (2019). Antibiofilm efficacy of curcumin in combination with 2-aminobenzimidazole against single- and mixed-species biofilms of Candida albicans and Staphylococcus aureus. Colloids Surf. B Biointerfaces. 174, 28-34. doi: 10.1016/j.colsurfb.2018.10.079

Theberge, S., Semlali, A., Alamri, A., Leung, K. P., and Rouabhia, M. (2013). C. albicans growth, transition, biofilm formation, and gene expression modulation by antimicrobial decapeptide KSL-W. BMC Microbiol. 13:246. doi: 10.1186/1471-2180-13-246

Trapnell, C., Pachter, L., and Salzberg, S. L. (2009). TopHat: discovering splice junctions with RNA-Seq. Bioinformatics. 25, 1105-1111. doi: 10.1093/ bioinformatics/btp 120

Vipulanandan, G., Herrera, M., Wiederhold, N. P., Li, X., Mintz, J., Wickes, B. L., et al. (2018). Dynamics of mixed Candida species biofilms in response to antifungals. J. Dent. Res. 97, 91-98. doi: 10.1177/00220345177 29351

Wang, T., Huang, W., Duan, Q., Wang, J., Cheng, H., Shao, J., et al. (2019). Sodium houttuyfonate in vitro inhibits biofilm dispersion and expression of bdlA in Pseudomonas aeruginosa. Mol. Biol. Rep. 46, 471-477. doi: 10.1007/s11033-0184497-9

Wang, T., Shao, J., Da, W., Li, Q., Shi, G., Wu, D., et al. (2018). Strong synergism of palmatine and fluconazole/Itraconazole against planktonic and biofilm cells of Candida species and efflux-associated antifungal mechanism. Front. Microbiol. 9:2892. doi: 10.3389/fmicb.2018.02892

Wu, D. Q., Cheng, H., Duan, Q., and Huang, W. (2015). Sodium houttuyfonate inhibits biofilm formation and alginate biosynthesis-associated gene expression in a clinical strain of Pseudomonas aeruginosa in vitro. Exp. Ther. Med. 10, 753-758. doi: 10.3892/etm.2015.2562

Xie, C., Mao, X., Huang, J., Ding, Y., Wu, J., Dong, S., et al. (2011). KOBAS 2.0: a web server for annotation and identification of enriched pathways and diseases. Nucleic Acids Res. 39, W316-W322. doi: 10.1093/nar/gkr483

Yang, X. Y., Shi, T., Du, G., Liu, W., Yin, X. F., Sun, X., et al. (2016). ITRAQ-Based Proteomics revealed the bactericidal mechanism of sodium new houttuyfonate against Streptococcus pneumoniae. J. Agric. Food Chem. 64, 6375-6382. doi: 10.1021/acs.jafc.6b02147

Ye, X., Li, X., Yuan, L., Ge, L., Zhang, B., and Zhou, S. (2007). Interaction of houttuyfonate homologues with the cell membrane of gram-positive and gramnegative bacteria. Colloids Surf. A Physicochem. Eng. Asp. 301, 412-418. doi: 10.1016/j.colsurfa.2007.01.012

Zhang, M., Chang, W., Shi, H., Zhou, Y., Zheng, S., Li, Y., et al. (2017). Biatriosporin D displays anti-virulence activity through decreasing the intracellular cAMP levels. Toxicol. Appl. Pharmacol. 322, 104-112. doi: 10.1016/ j.taap.2017.03.004

Zhao, Y., Si, Y., Mei, L., Wu, J., Shao, J., Wang, C., et al. (2019). Effects of sodium houttuyfonate on transcriptome of Pseudomonas aeruginosa. BMC Res. Notes. 12:685. doi: 10.1186/s13104-019-4721-2

Znaidi, S., Nesseir, A., Chauvel, M., Rossignol, T., and d'Enfert, C. (2013). A comprehensive functional portrait of two heat shock factor-type transcriptional regulators involved in Candida albicans morphogenesis and virulence. PLoS Pathog. 9:e1003519. doi: 10.1371/journal.ppat.1003519

Conflict of Interest: The authors declare that the research was conducted in the absence of any commercial or financial relationships that could be construed as a potential conflict of interest.

Copyright (c) $2020 \mathrm{Wu}, \mathrm{Wu}$, Zhao, Si, Mei, Shao, Wang, Yan and Wang. This is an open-access article distributed under the terms of the Creative Commons Attribution License (CC BY). The use, distribution or reproduction in other forums is permitted, provided the original author(s) and the copyright owner(s) are credited and that the original publication in this journal is cited, in accordance with accepted academic practice. No use, distribution or reproduction is permitted which does not comply with these terms. 